Chapman University

Chapman University Digital Commons

7-2021

\title{
Making It Public: The Effect of (Private and Public) Wage Proposals on Efficiency and Income Distribution
}

Lara Ezquerra

Joaquín Gómez-Miñambres

Natalia Jiminez

Praveen Kujal

Follow this and additional works at: https://digitalcommons.chapman.edu/esi_working_papers

Part of the Econometrics Commons, Economic Theory Commons, and the Other Economics Commons 
Making It Public: The Effect of (Private and Public) Wage Proposals on Efficiency and Income Distribution

Comments

ESI Working Paper 21-12 


\title{
Making it public: The effect of (private and public) wage proposals on efficiency and income distribution
}

\author{
Lara Ezquerra $^{+}$, Joaquín Gómez-Miñambres ${ }^{++}$, Natalia Jimenez*,** and Praveen Kujal**1
}

\begin{abstract}
:
The implications of (public or private) pre-play communication and information revelation in a labour relationship is not well understood. We address these implications theoretically and experimentally. In our baseline experiments, the employer offers a wage to the worker who may then accept or reject it. In the public and private treatment, workers, moving first, make a non-binding private or public wage proposal. Our theoretical model assumes that wage proposals convey information about a worker's minimum acceptable wage and are misreported with a certain probability. It predicts that, on average, wage proposals lead to higher wage offers and acceptance rates, with the highest wages under private proposals. While both, public and private, proposals increase efficiency over the baseline, private proposals generate higher worker incomes. Broad support for the theoretical predictions is found in the laboratory experiments. Our work has important implications for recent policies promoting public information on wage negotiations. We find that while wage proposals promote higher wages, efficiency, and income equality, public information on wage negotiations is likely to benefit firms more than workers.
\end{abstract}

Keywords: wage negotiations, cheap talk, laboratory experiments, ultimatum game, wage proposals.

JEL: C90, C72, J31, M52

\footnotetext{
${ }^{1}+$ Universidad de las Islas Baleares, Spain. ++ Lafayette College \& Economic Science Institute, Chapman University. ORCID: https://orcid.org/0000-0001-5765-189X., * Universidad Pablo Olavide, Spain,** Middlesex University, U.K. https://orcid.org/0000-0002-2917-9724. We are grateful to seminar participants from ESI Chapman, Middlesex University and SEET meetings.
} 


\section{Introduction}

Albeit cheap talk, employers frequently ask workers for their expected wages in negotiations. The practice is common in professional sports, senior level management, academic hiring and many other highly skilled jobs. Proposals can take many forms with one-to-one negotiations to centralized mechanisms such as unions (at the firm, industry or national level) making wage proposals to employers. Despite their widespread use, these forms of wage institutions have been largely ignored. ${ }^{2}$

In this paper, we study pre-play communication in a laboratory experiment of employment relationships where workers can make a non-binding wage proposal to their employer. Our baseline follows the design of Falk, Fehr and Zehnder (2006) which looks at the traditional ex-ante wage posting structure (ultimatum game) where the employer makes wage offers to two workers. The worker can either accept or reject. On acceptance full surplus is realised, while zero surplus is obtained in the case of a rejection. We then modify this setting to allow for workers to first make private wage proposals that are non-binding for the firm. Firms observe the proposals and can then choose to make an offer that the worker may accept or reject. ${ }^{3}$ In the final treatment, we allow for public observability of past proposals for each worker pair at the end of each period ${ }^{4}$. We focus on the effect that different wage proposals have on the outcomes of the employment relationship. By comparing the effects of proposals with the baseline, we can study how pre-play communication affects wages, income distribution and overall efficiency. Our setting allows us to answer novel and interesting research questions: Are wage offers higher when workers are allowed to make ex-ante proposals? Do proposals increase the probability of accepting wage offers (and hence efficiency)? Who benefits from making wage proposals public information to other workers?

To provide testable hypotheses for our experiment, we develop a theoretical framework that relies on the idea that workers' wage proposals are pre-play cheap talk (see Farrell and Rabin 1996 for a review). In our model, non-binding proposals may convey information about the worker's minimum acceptable wage with workers misreporting their private information with a certain positive probability. As a result, the optimal wage offer by the firm is a function of the workers" wage proposals (which may be "partially" or “fully” revealing to the employer).

\footnotetext{
${ }^{2}$ See, Caju, Gautier, Momferatou and Ward-Warmedinger (2008) for details on different forms of wage bargaining institutions. ${ }^{3}$ This is the ultimatum game version of the labor market institution where rejection of an offer results in zero surplus to both workers and the firm. In fact, most traditional markets are of this nature, where a rejection of an offer from one side results in zero surplus for both. A structure with counter proposals would be akin to a double auction or a bargaining framework.

${ }^{4}$ Our private and public proposals treatments resemble the design in Rigdon (2012) (demand side) ultimatum game experiment. Rigdon's research goal is to analyse the gender wage gap under private proposals and whether it can be mitigated with public information. Therefore, our focus is quite different from hers.
} 
We show that if we have a mix of "revealing" and "partially revealing" workers then the final wage offer will be increasing in the proposals as the firm faces a trade-off between the possibility of rejection of low offers and acceptance of higher ones. This simple intuition also sets the stage for our main theoretical hypothesis. First, we expect firm's wage offers to be increasing in proposals. This implies that average wage offers under proposals should be greater than in the baseline (with no proposals). We also expect wage proposals to increase acceptance rates (and hence efficiency) relative to the baseline. Finally, due to conformity, public proposals make workers more likely to accept lower wages and hence, relative to private proposals, public proposals generate not only lower wages but also higher firm profits and a more equal income distribution.

Our experimental results are broadly consistent with our theoretical predictions. Overall, they indicate that introducing proposals prior to firm wage-setting decisions has important efficiency and distributional consequences. While wage proposals always increase efficiency, workers (firms) benefit more when proposals are private (public). ${ }^{5}$ Though not a direct test, our experimental results have implications for policy makers as we find the potential efficiency and distributional consequences of proposals that are a widely used instrument in wage negotiations. In our experimental setup public proposals benefit the firm that earns higher profits, while private proposals are more conducive towards improving workers' wages. Moreover, both type of wage proposals increase income equality among workers. On the other hand, we also find that the baseline without proposals is the most inefficient setting while also leading to the highest levels of income inequality. In a nutshell, our results indicate that while both types of wage proposals lead to higher wages, income equality and efficiency, public information benefits firms more than workers. While this finding runs counter to popular opinion on the effects of wage transparency, it is very much in line with recent field evidence showing that making the outcomes of wage negotiations public reduces individual workers' bargaining power and hence wages (Cullen and Pakzad-Hurson, 2021). We suggest that a possible explanation for this is that, under public information, workers are more willing to conform to the proposals of others and less likely to reject wage offers.

\footnotetext{
${ }^{5}$ While not our main focus, we also look at gender effects in our experiment (see Section 5.3). Wage proposals could be another avenue for gender wage discrimination if females have lower willingness to accept/propose. We find that making proposals privately (publicly), tend to increase male (female) wage proposals and hence overall income. Even though these differences are not statistically significant, this pattern of behavior resembles the "catch up" result in Rigdon (2012).
} 
The remainder of the paper is organized as follows. We review the literature in Section 2. We describe the experimental design and procedures in Section 3. We present our theoretical model in Section 4. The main results are reported in Section 5 and we conclude in Section 6.

\section{Literature Review}

The only paper that analyses (average) wage proposals, in a relationship between firms and workers is Bottino, García-Muñoz, Goddio and Kujal (2016). They studied the effect of worker entitlement to a wage on a gift exchange game. Their structure resembles that of a workers' union making a non-binding single wage proposal to firms on behalf of a worker's collective. An average non-binding wage proposal is presented to employers from the workers, who then independently respond by making wage offers in a double auction format (a la Fehr, Kirchsteiger and Riedl, 1993). While average wages slightly increase, they find a negative relation between effort and wage expectations. The main difference with our study is that we present worker proposals to firms at an individual level. Additionally, we don't consider effort levels to control for reciprocity effects. Also, they use a double auction set-up that as used in gift exchange experiments. We model a firm-worker relationship where offers are posted and can be only accepted or rejected.

Another paper that also uses proposals in a (Demand Side) Ultimatum game to study the gender wage gap is Rigdon (2012). She finds that females ask for less and earn smaller amounts than their male counterparts. In her framework workers make proposals that are made public in a subsequent treatment. Making proposals public, i.e. proposals being made by others in a similar negotiating situation, directly influences the beliefs women have about proposals in the ultimatum game. Consequently, they ask for more, thus eliminating the negotiation gap and eliminating the gender gap in wages. In contrast to our study, Rigdon does not study a labour market interaction and uses a Demand Side Ultimatum Game. Additionally, the experiment does not consider a baseline treatment without proposals (since her research goal is quite different to ours) and her framework cannot be used to assess the overall effects of wage proposals. ${ }^{6}$

\footnotetext{
${ }^{6}$ Yamamori et al. (2008) conducted a dictator game experiment in which the recipient states a request for the minimum offer that they are willing to receive before the dictator dictates their offer, finding that the latter increases as the recipient's request increases to half of the share. Albeit in a quite different setting, their finding is in line with our own result that wage offers tend to increase with workers' proposals.
} 
Besides the abovementioned papers there is an experimental literature on negotiation related with our study. Their focus, however, is on the gender gap. Some of them consider the Ultimatum Game (Eckel and Grossman, 2001 and García-Gallego, Georgantzís and JaramilloGutiérrez, 2012), while others use different versions of negotiation games with several stages (Hernandez-Arenaz and Iriberri, 2018 and Exley, Niederle and Vesterlund, 2020). We will provide further details of these studies in the results section where we report our findings on gender.

Cheap talk can be interpreted as the weakest form of worker participation where firms consider credible workers' communication with a certain probability. Therefore, our research also adds to the literature on worker involvement in the wage participation process (Charness, et al. 2012, Charness et al. 2016, Jeworrek and Mertins, 2014, Franke, Gurtoviy and Mertins, 2016, among others). Worker participation in the wage determination process occurs in many forms in the workplace. It can be through wage bargaining, centralised or decentralised, or direct participation of workers in the wage process. The latter has been studied in the lab (Charness et al. 2012) and the field (Jeworrek and Mertins, 2014). Other factors that have been studied are social comparison (Charness et al. 2016) or choosing from a menu of options (Franke, Gurtoviy and Mertins, 2016). The majority of this research, experimental or field, broadly confirms that worker participation increases worker productivity.

Charness et al. (2016) argue that social comparison is important in labour markets and may affect one's attitude towards an employer or intrinsic motivation. This is similar to our idea of conformity (Cialdini and Goldstein, 2004), when rival proposals are public, where workers observe proposals of a worker from an earlier period. The only channel through which conformity works in our setup is through adjustment of wage proposals. Our idea of conformity assumes that a worker's proposal will mimic the co-worker's previous proposal (Charness et al. 2016).

A comment is due as to whether the behavioral traits identified in the experiment are present or applicable in markets outside the laboratory. While external validity is always an issue in any laboratory (or field) experiment, what is important is that qualitative results guide us in the right direction (see Kessler and Vesterlund, 2015 and Camerer, 2015). There is evidence that many of the behavioural traits observed in the laboratory are observed with high stakes (Cameron, 1999; Slonim and Roth, 1998; Fehr, Fischbacher, and Tougareva, 2002: Jeworrek and Mertins, 2014) or extend to real world situations. Jeworrek and Mertins (2014) find that a managerial policy of allowing employees to self-determine their wages, as had been suggested by laboratory evidence, extends to the field. They find that this policy indeed 
enhances performance. Güth, Schmidt and Sutter (2007) compare an Ultimatum Game (UG hereafter) where participants were students and another UG where participants were newspaper's readers and they found that results are similar, so there is a high degree of students population data validity. Dyer, Kagel and Levin (1989) find that professionals also are subject to the winner's curse. Fairness concerns also play a prominent role in firm's wage policies (Bewley and Bewley, 2009; Agell and Bennmarker, 2003) while, recent papers indicate that laboratory measures of social preferences can be good predictors of behavior in field settings. Karlan (2005) shows that reciprocity (i.e., trustworthiness) in trust games predicts subjects' loan repayments one year after a laboratory experiment, and Carpenter and Seki's work (2005) suggests that laboratory measures of conditional cooperation forecast productivity in the workplace. Finally, laboratory experiments have long been used by policy makers as a guide, i.e. to provide qualitative insights. The Arizona Corporation Commission (ACC) used laboratory experiments to gain insights into incentive regulation (see Cox and Isaac, 1986 and Rassenti and Smith, 1986). Laboratory experiments were then further used as a guide to inform electric decentralization/privatization in US, Australia and New Zealand (Rassenti, Smith and Wilson, 2002). Therefore, while we do not wish to downplay the importance of field evidence on salary negotiations, we also believe that laboratory experiment can be seen as a promising first step to shed light on real world issues.

\section{Experimental design}

The experiment was conducted at the Universidad Pablo de Olavide in Seville (Spain) using zTree software (Fischbacher, 2007). It consisted of 12 sessions (four per treatment) with 219 participants in total, who were recruited online using ORSEE (Greiner, 2015). No one was allowed to participate in more than one session. The average length of a session was around 70 minutes and average earnings were $10.95 €$.

Our design is a slightly modified version of the game in Falk, Fehr and Zehnder (2006). Participants were randomly assigned a role as either a firm or a worker and the role was fixed for the entire duration of the experiment. In each period, a firm was randomly matched with two workers. Subjects read the instructions once roles were assigned to participants. ${ }^{7}$ To make sure they understood the instructions, all participants had to answer some questions after

\footnotetext{
${ }^{7}$ The instructions were first read individually and then aloud by the experimenter.
} 
finishing the instructions (see Appendix A2 for further details). They could only participate in the experiment on successfully answering all questions. The experiment lasted 15 periods.

The basic structure, common to all treatments, was as follows. In the first stage, the firm decided whether to make a wage offer to each worker or not. ${ }^{8,9}$ In the second stage, workers receiving an offer decided whether to accept it or reject it. The surplus was only realized when a contract was mutually agreed upon between a worker and a firm. A rejected offer implied that neither the firm nor the worker realized any gains. To avoid potential confounding regarding reciprocity concerns, workers were homogenous and did not differ in their productivity levels. We considered three different experimental treatments:

Baseline (BASE): A firm could make a wage offer, or not, to one or both the workers. A worker receiving an offer decides whether to accept it or reject it. Worker information was private, and they only knew if they received an offer or not. They could also see their past offers. Similarly, a firm could observe the entire history of her own past actions and earnings.

Private proposals (PRIV): Prior to Stage 1 of the BASE, workers first made a private "wage proposal" to the firm. Firms knew that the proposals were not binding, and they could make an alternate (or no) wage offer.

Public proposals (PUB): The only difference with PRIV is that workers could see the co-workers' past proposals at the end of each period.

\begin{tabular}{|c|c|c|}
\hline \multicolumn{3}{|c|}{ Table 1: Experimental design } \\
\hline Treatment & Description & Time Line \\
\hline & $\begin{array}{l}\text { Firms could make } 0 / 1 / 2 \\
\text { private wage offers in }\end{array}$ & Stage 1 \\
\hline
\end{tabular}

${ }^{8}$ Following Falk, Fehr and Zehnder (2006), we frame the instructions as employer, employee and wages (see instructions in Appendix A1).

${ }^{9}$ The firm-worker framing is also used in García-Gallego, Georgantzís and Jaramillo-Gutiérrez (2012). 


\begin{tabular}{|c|c|c|c|c|c|}
\hline $\begin{array}{c}\text { Baseline } \\
\text { (BASE) }\end{array}$ & $\begin{array}{l}\text { Stage-1. Workers accepted } \\
\text { or rejected the offers. } \\
\text { They own past offers. Firms } \\
\text { saw own past actions and } \\
\text { worker decisions. }\end{array}$ & $\begin{array}{l}\text { Firm: } \\
\text { Wage offer }\end{array}$ & $\begin{array}{l}\text { Worker: } \\
\text { Accepts/Reje }\end{array}$ & ects & \\
\hline $\begin{array}{l}\text { Private } \\
\text { Proposals } \\
\text { (PRIV) }\end{array}$ & $\begin{array}{l}\text { Workers made non-binding } \\
\text { "wage proposals" to the } \\
\text { firms before the wage offer } \\
\text { + BASE }\end{array}$ & $\begin{array}{l}\text { Stage } 1 \\
\text { Worker: } \\
\text { Wage proposal }\end{array}$ & $\begin{array}{l}\text { Stage } 2 \\
\text { Firm: } \\
\text { Wage offer }\end{array}$ & $\begin{array}{l}\text { Stage } 3 \\
\text { Worker: } \\
\text { Accepts/Reject }\end{array}$ & \\
\hline $\begin{array}{l}\text { Public } \\
\text { Proposals } \\
\text { (PUB) }\end{array}$ & $\begin{array}{l}\text { PRIV + workers could see } \\
\text { all the other workers' past } \\
\text { proposals. }\end{array}$ & $\begin{array}{l}\text { Stage } 1 \\
\text { Worker: } \\
\text { Wage proposal }\end{array}$ & $\begin{array}{l}\text { Stage } 2 \\
\text { Firm: } \\
\text { Wage offer }\end{array}$ & $\begin{array}{l}\text { Stage } 3 \\
\text { Worker: } \\
\text { Accepts/Rejects }\end{array}$ & $\begin{array}{l}\text { Stage } 4 \\
\begin{array}{l}\text { Worker: } \\
\text { proposal } \\
\text { revealed }\end{array}\end{array}$ \\
\hline
\end{tabular}

Note: There were 4 sessions per treatment, 25 firms and 50 workers in BASE, 24 firms and 48 workers in both PRIV and PUB.

If an offer was accepted, the worker received the agreed wage and the firm earned 390 points (see exchange rates below) minus the wage offer. Earnings for firms and workers are summarized in Table 2, where $w_{i}$ denotes the wage offer for the worker, $i=\{1,2\}$.

\begin{tabular}{|c|c|l|c|c|}
\hline \multicolumn{5}{|c|}{ Table 2: Payoffs } \\
\hline Total offers & Total surplus & $\begin{array}{l}\text { Worker } \\
\text { decision }\end{array}$ & Firm Profits & $\begin{array}{l}\text { Worker } \\
\text { earnings }\end{array}$ \\
\hline 0 & 0 & - & 0 & 0 \\
\hline \multirow{2}{*}{1} & \multirow{2}{*}{390} & Accept & $390-\mathrm{w}_{\mathrm{i}}, \mathrm{i}=1,2$ & $\mathrm{w}_{\mathrm{i}}, \mathrm{i}=1,2$ \\
\cline { 3 - 5 } & \multirow{2}{*}{2} & Reject & 0 & 0 \\
\hline & 780 & Accept & $780-\left(\mathrm{w}_{1}+\mathrm{w}_{2}\right)$ & $\mathrm{w}, \mathrm{W}=1,2$ \\
\cline { 3 - 5 } & & Reject & 0 & 0 \\
\hline
\end{tabular}

At the end of the experiment, participants answered a questionnaire that included age, gender, zip code, studies, self-reported fair wage, reasons for wage discrimination (only for firms), Cognitive Reflection Test (Toplak, West and Stanovich, 2014), risk aversion (Bomb Risk Elicitation Task by Crosetto and Filippin, 2013) and the difficulty to recognize own mistakes (for further details on these questions see Appendix A3). The answers to this questionnaire allows us to control for subject heterogeneity. 
The payoff functions, the number of rounds and the matching protocol were common information for participants in all treatments. Everyone was informed that they will be paid for one out of the 15 rounds randomly chosen, but they were only informed about their own exchange rate at the start of the experiment. ${ }^{10}$ Exchange rates were set to have comparable payoffs across participants. The exchange rate for firms was 1 euro $=17.73$ points and 1 euro $=21.67$ points for workers.

In all treatments, firms could only see their own wage offers and payoffs for current and previous periods at the end of each period. Additionally, under PRIV firms were also informed about wage proposals in the current and all previous periods, while workers were also informed about their own wage proposals after period one. Finally, in PUB workers were informed about the history of the other co-worker's wage proposals from all past periods for that match.

\section{The theoretical model}

In this section, we describe a theoretical framework that formalizes the key elements of our experiment. This is done to obtain testable hypothesis regarding overall treatment differences. Below we describe the basic model and discuss the experimental hypotheses.

We consider an ultimatum game between a "worker" (he) and a "firm" (she). Let $M \in \mathbb{R}_{+}$ be the endowment to be divided between the two parties. In our basic framework, the firm offers a wage to the worker, $w_{o} \leq M$, which in turn decides whether to accept or reject. If the firm's offer is accepted, the worker receives $w_{o}$ and the firm collects $M-w_{o}$. If the offer is rejected, both parties end up with 0 . For simplicity, we assume risk neutrality which involves linear utility functions over wealth (i.e., $M-w_{o}$ for the firm and $w_{o}$ for the worker). ${ }^{11}$

Consistent with results in ultimatum games (see Camerer, 2011, pp.48-63 for a review) we assume that the worker has a minimum acceptable wage $w_{m} \leq M \cdot{ }^{12}$ Thus, the worker will accept (reject) a firm's offer if $w_{o} \geq w_{m}\left(w_{o}<w_{m}\right)$. The worker's minimum acceptable wage can be of two types, low and high, indexed by $i \in\{L, H\}$ where $M \geq w_{m, H}>w_{m, L} \geq 0$. We

\footnotetext{
${ }^{10}$ By informing subjects of their exchange rate at the start of the experiment, we are more likely to prevent feelings of disappointment and increase their willingness to participate in future experiments (Blount and Bazerman, 1996).

${ }^{11}$ None of the main predictions that we test in our experiment would change if we assumed risk aversion. Only the quantitative results might be different. It is easy to check that the wage offer should increase with the firm's level of risk aversion.

${ }^{12}$ Note that the existence of a minimum acceptable wage is also consistent with previous papers on rules of fairness in the workplace (e.g., Akerlof, 1982; Kahneman, Knetsch and Thaler, 1986; Bottino, García-Muñoz, Goddio and Kujal, 2016). According to this interpretation $w_{m}$ represents the worker's 'reference wage', that is, his idiosyncratic idea of a fair compensation.
} 
denote by $q$ the proportion of workers with a low minimum acceptable wage $\left(w_{m, L}\right)$ in the population. ${ }^{13}$

\subsection{Baseline (BASE)}

We begin by solving the model where the firm does not have any more information about the worker's type other than the commonly known prior $(q)$. This corresponds to our Baseline (BASE) treatment. In this case, the firm decides whether to offer a high wage $\left(w_{o}=w_{m, H}\right)$ that both worker types would accept or, offer a low wage $\left(w_{o}=w_{m, L}\right)$ that will be accepted only with probability $p$. We denote by $T=\frac{M-w_{m, H}}{M-w_{m, L}}$ the firm's profits from a high offer relative to the firm's profits from a low offer that was accepted. Therefore, $T<1$ is a measure of the relative profitability of making a high wage offer. In the proposition below we provide the optimal wage $\left(w_{0}^{B A S}\right)$ and the corresponding expected firm's profits $\left(\Pi_{F}^{B A S}\right)$, expected worker's income $\left(\Pi_{W}^{B A S}\right)$ and the acceptance rate $\left(r^{B A S E}\right)$. All proofs are relegated to Appendix B.

Proposition 1 (BASE): The optimal wage offered by the firm, and the corresponding expected firm's profits, expected worker's income and the acceptance rate are given by:

$$
\begin{gathered}
w_{o}^{B A S E}=\left\{\begin{array}{l}
w_{m, L} \quad \text { if } q \geq T \\
w_{m, H} \quad \text { if } q<T
\end{array} ; \Pi_{F}^{B A S E}=\left\{\begin{array}{l}
q\left(M-w_{m, L}\right) \quad \text { if } q \geq T \\
M-w_{m, H} \quad \text { if } q<T
\end{array}\right.\right. \\
\Pi_{W}^{B A S E}=\left\{\begin{array}{ll}
q w_{m, L} & \text { if } q \geq T \\
w_{m, H} & \text { if } q<T
\end{array} ; r^{B A S E}= \begin{cases}q & \text { if } q \geq T \\
1 & \text { if } q<T\end{cases} \right.
\end{gathered}
$$

where $T=\frac{M-w_{m, H}}{M-w_{m, L}}$.

Thus, the firm makes a low offer when the proportion of low types in the population is high enough ( $q$ is high) and/or when making a high offer is relatively unprofitable ( $T$ is low), otherwise the firm makes a high offer. The low offer would be accepted only with probability $q$, while a high offer would be accepted by all workers.

\subsection{Private Proposals (PRIV)}

\footnotetext{
${ }^{13}$ In a previous version we proposed a general version of this model where the minimum acceptable wage follows a uniform continuous distribution (the document is available upon request). Our main qualitative results and predictions were not affected by this assumption. We thus focus on the two-type model for the sake of simplicity and clarity of exposition.
} 
We now consider a modified version of the ultimatum game in which the worker moves first by sending a non-binding wage proposal to the firm, $w_{p} \leq M$. After receiving the wage proposal, the firm decides the wage offer. The worker can then accept or reject the firm's offer. Below is the timeline for this game.

Following insights from the cheap talk literature (see Farrell and Rabin 1996 for a review) we study a situation where the wage proposal conveys information about the worker's minimum acceptable wage $\left(w_{m, i}\right)$, with the possibility that the worker might be misreporting their private information. In particular, we assume that the low type worker's proposal is their minimum acceptable wage (i.e., reports truthfully) with probability $\lambda \in(0,1) .{ }^{14}$ However, with probability $1-\lambda$ the low type proposes $w_{p}=w_{m, H}$ (i.e., she misreports). ${ }^{15}$ Therefore, when observing a high wage proposal the firm does not know whether the worker is truly a high type, or a low type who is misreporting. The assumption that the worker, when proposing a wage to the firm, does not always misreport his minimum acceptable wage is consistent with the "aversion to lying" literature (e.g., Gneezy, 2005; Lundquist et al. 2009). Moreover, for simplicity, we do not formalize whether it is optimal for the low type worker to misreport or not, and simply assume that this occurs with a commonly known probability $(1-\lambda)$.

Note that, in our model, low proposals $w_{p}=w_{m, L}$ (which arise with probability $\lambda q$ ) are "fully revealing" for the firm, because only a low type who is truthfully reporting would make such a low proposal. However, observing $w_{p}=w_{m, H}$ is only "partially revealing" because such a proposal might have come from a high type (with probability $(1-q)$ ) or from a low type who is misreporting (with probability $q(1-\lambda)$ ). It is easy to see that the firm would always meet the worker's proposal when it is "fully revealing". If, however, the wage proposal is "partially revealing" then the firm needs to consider the trade-off between the benefit of offering $w_{m, L}$ if the worker is misreporting, and the loss that comes from a rejection if the worker's proposal was his minimum acceptable wage, $w_{m, H}$. In other words, the firm decides

\footnotetext{
${ }^{14}$ According to Farrell and Rabin (1996): "[P]eople typically say what they want to have been believed even when the incentives clearly imply that cheap talk should not be believed, [that is] some people tell the truth despite incentives to lie" (p.104). However, that some people always propose their minimum acceptable wage is not key assumption in our model. Our main results would remain unchanged if we assume that everybody misreports, as long as some misreport more than others.

${ }^{15}$ In the continuous version of this model (available upon request) workers can misreport by a factor $b>0$. The two-type model is essentially a particular case of the continuous model where $b=w_{m, H}-w_{m, L}$. The assumption that only the low type misreports is also captured in the continuous version because, given that the maximum report is $M$, those with a high minimum acceptable wage $\left(w_{m}>M-b\right)$ cannot fully misreport; and those with $w_{m}=M$ will not misreport at all. Therefore, a high proposal in the continuous case is more indicative that the worker is not misreporting. Finally, note that in the discrete model, results would not be different if we allow the high type to misreport as well; this is because such a misreport will always be detected, and hence ignored, by the firm.
} 
whether it pays off to believe the worker or not. In the following proposition we summarize the results of the private proposals case.

Proposition 2 (PRIV): The optimal wage policy and the corresponding expected firm profits, expected worker income and the acceptance rate are given by:

$$
\begin{gathered}
w_{o}^{P R I V}=\left\{\begin{array}{l}
w_{m, L} \text { if } w_{p}=w_{m, L} \\
\widetilde{w}_{o}^{P R I V} \quad \text { if } w_{p}=w_{m, H}
\end{array} \text { where } \widetilde{w}_{o}^{P R I V}=\left\{\begin{array}{ll}
w_{m, L} & \text { if } \hat{q}^{P R I V} \geq T \\
w_{m, H} & \text { if } \hat{q}^{P R I V}<T
\end{array} ;\right.\right. \\
\Pi_{F}^{P R I V}=\left\{\begin{array}{l}
q\left(M-w_{m, L}\right) \\
M-w_{m, H}+q \lambda\left(w_{m, H}-w_{m, L}\right) \text { if } \hat{q}^{P R I V}<T
\end{array}\right. \\
\Pi_{W}^{P R I V}=\left\{\begin{array}{ll}
q w_{m, L} & \text { if } \hat{q}^{P R I V} \geq T \\
w_{m, H}-q \lambda\left(w_{m, H}-w_{m, L}\right) & \text { if } \hat{q}^{P R I V}<T
\end{array} ; r^{P R I V}=\left\{\begin{array}{lll}
q & \text { if } & \hat{q}^{P R I V} \geq T \\
1 & \text { if } & \hat{q}^{P R I V}<T
\end{array}\right.\right.
\end{gathered}
$$

where $=\frac{M-w_{m, H}}{M-w_{m, L}}, \hat{q}^{P R I V}=P\left(w_{m, L} \mid w_{p}=w_{m, H}\right)=\frac{(1-\lambda) q}{1-q \lambda}<q$, and $\widetilde{w}_{o}^{P R I V}$ is the optimal wage offer conditional on the wage proposal being high.

When a worker first makes a proposal, he is sending a signal to the firm about his minimum acceptable wage. While proposing $w_{m}^{H}$ is only partially revealing, it decreases the firm's belief that the worker is low type (i.e., $\hat{q}^{P R I V}<q$ ). As a result, when the proposal is high, the firm is less likely to offer a low wage offer in PRIV than in BASE. Consequently, expected worker's income should increase with proposals. However, as we show in the corollary below, because acceptance rates will be higher, firms' might also be strictly better off under proposals.

Corollary 1 (PRIV vs. BASE): Comparing the results when private proposals are available $(P R I V)$ with the results without proposals (BASE), we find that:

$$
w_{o}^{P R I V} \geq w_{o}^{B A S E} ; \Pi_{F}^{P R I V} \geq \Pi_{F}^{B A S E} ; \Pi_{W}^{P R I V} \geq \Pi_{W}^{B A S E} \text { and } r^{P R I V} \geq r^{B A S E}
$$

\subsection{Public Proposals (PUB)}

We now proceed to discuss an extension of the previous model where workers are informed about a co-worker's previous wage proposal. We assume that after a first period with private proposals, there is a second period where the worker learns about the proposal made by the coworker in the previous period ${ }^{16}$. The extension allows us to consider the possibility that workers

16 This structure resembles the PUB treatment in our experiment. 
change their proposal to conform to others'. Social psychologists refer to conformity as "the act of changing one's behavior to match the responses of others" (Cialdini and Goldstein, 2004, p. 606). Conformity is not only widespread, but also at the root of important findings in the economic literature (see, e.g., Bernheim, 1994; Clark and Oswald, 1998; Sliwka, 2007; Thöni and Gächter, 2015). ${ }^{17}$

We capture conformity in our model by assuming that a worker's proposal in PUB will mimic the co-worker's previous proposal. Therefore, instead of being purely random, the low type worker's decision to misreport in PUB is affected by the co-workers' previous proposal. However, although a low type (i.e., $w_{m, L}$ ), observes a high proposal by his co-worker, this worker will keep his type fixed. Moreover, our notion of conformity also implies that when a worker, who was initially of the high type (i.e., $w_{m, H}$ ), is informed of a low proposal, i.e. $w_{p, c}=w_{m, L}$, the worker will then also make a similar low wage proposal $\left(w_{p}^{P U B}=w_{m, L}\right)$. This, in effect, makes the worker a low type because, in our model, he cannot reject an offer that meets his proposal. ${ }^{18}$ Thus, although both types of workers mimic their co-workers proposals, only high types indeed change their type (to low).

In the following figure, we show that the worker's proposal, given his initial minimum acceptable wage (and type), has a low minimum acceptable wage in PUB and all possible subsequent matches. From Figure 3 we can compute the total probability of the worker being of low type in PUB: $q^{P U B}:=P\left(w_{m}^{P U B}=w_{m, L}\right)=q(1+(1-q) \lambda)>q$. Therefore, our notion of conformity implies that there will be more low type workers in PUB than in PRIV, which is a key driver of the results in this section. In the following proposition we summarize the results for the public proposal case.

\footnotetext{
${ }^{17}$ Conformity is a type of "social influence": the fact that a person's emotions, opinions or behaviors are affected by others. There are two types of conformity, "normative influence" is often used to refer to situations in which individuals are susceptible to social influence in order to conform to or identify with others (Festinger, Schachter and Back, 1950; Asch, 1953; Cai, Chen and Fang, 2009; and Fatas, Heap and Arjona, 2018). Alternatively, "informational influence" (also known as "social proof") is used to describe social influence in a context in which the behavior of others is useful in order to infer inaccessible information about an objective state of the world (Banerjee 1992; Anderson and Holt, 1997; Goeree and Yariv, 2015; and Muchnik, Aral and Taylor, 2013). In this paper, we are agnostic about what type of conformism is more likely to affect subjects' behaviour (but they are not mutually exclusive). Thus, our assumption is that people conform but we do not enter into the reasons why people conform.

${ }^{18}$ Note that, for simplicity, we are assuming that neither firms nor workers are forward looking and hence the results in PRIV are unaffected by adding a new interaction in PUB.
} 


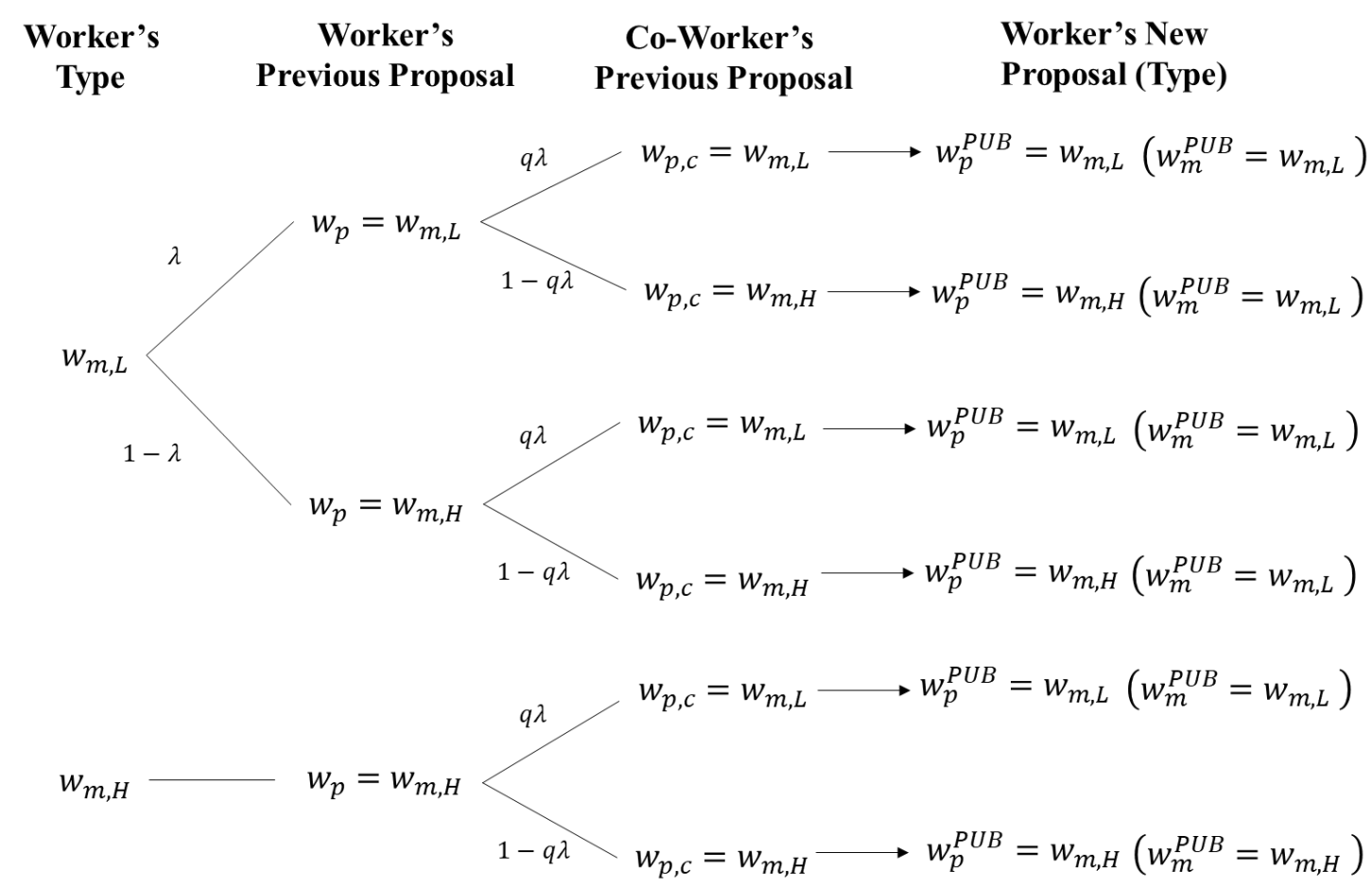

Figure 3. Worker's proposal (and type) in PUB given own and co-worker's previous proposal.

Proposition 3 (PUB). The optimal wage policy and the corresponding expected firm's profits, expected worker's income and acceptance rates are given by:

$$
\begin{aligned}
& w_{o}^{P U B}=\left\{\begin{array}{ll}
w_{m, L} & \text { if } w_{p}=w_{m, L} \\
\widetilde{w}_{o}^{P U B} & \text { if } w_{p}=w_{m, H}
\end{array} \text { where } \widetilde{w}_{o}^{P U B}=\left\{\begin{array}{ll}
w_{m, L} & \text { if } \hat{q}^{P U B} \geq T \\
w_{m, H} \quad \text { if } \hat{q}^{P U B}<T
\end{array} ;\right.\right. \\
& \Pi_{F}^{P U B}=\left\{\begin{array}{c}
q^{P U B}\left(M-w_{m, L}\right) \quad \text { if } \hat{q}^{P U B} \geq T \\
M-w_{m, H}+q^{P U B} \lambda\left(w_{m, H}-w_{m, L}\right) \text { if } \hat{q}^{P U B}<T
\end{array}\right. \\
& \Pi_{W}^{P U B}=\left\{\begin{array}{c}
q^{P U B} w_{m, L} \quad \text { if } \hat{q}^{P U B} \geq T \\
w_{m, H}-q^{P U B} \lambda\left(w_{m, H}-w_{m, L}\right) \text { if } \hat{q}^{P U B}<T
\end{array} ; r^{P U B}=\left\{\begin{array}{cc}
q^{P U B} & \text { if } \hat{q}^{P U B} \geq T \\
1 & \text { if } \hat{q}^{P U B}<T
\end{array}\right.\right.
\end{aligned}
$$

where $T=\frac{M-w_{m, H}}{M-w_{m, L}}, \quad q^{P U B}=P\left(w_{m}^{P U B}=w_{m, L}\right)=q(1+(1-q) \lambda)>q, \hat{q}^{P U B}=P\left(w_{m}^{P U B}=\right.$ $\left.w_{m, L} \mid w_{p}=w_{m, H}\right)=\frac{1-\lambda q}{1-\lambda q q^{P U B}}>\hat{q}^{P R I V}$, and $\widetilde{w}_{O}^{P U B}$ is the optimal wage offer conditional on the wage proposal being high.

We can use Propositions 1-3 to compare results across our three treatments. In the next corollary, we focus on the most interesting case in which the firm finds it optimal to 
discriminate between proposals in PRIV; while the wage offer in PUB and BASE can be rejected.

Corollary 2 (PUB vs. PRIV vs. BASE). If $T \in\left(\hat{q}^{P R I V}, q\right]$ then:

$$
\widetilde{w}_{o}^{P R I V}=w_{m, H}>w_{m, L}=\widetilde{w}_{o}^{P U B}=w_{o}^{B A S E}
$$

In this case, we have,

$$
\begin{gathered}
\Pi_{F}^{P U B}>\Pi_{F}^{P R I V} \geq \Pi_{F}^{B A S E} \\
\Pi_{W}^{P R I V}>\Pi_{W}^{P U B}>\Pi_{W}^{B A S E} \\
r^{P R I V}=1>r^{P U B}>r^{B A S E}
\end{gathered}
$$

Therefore, under the conditions of Corollary 2 we obtain a clear ranking of outcomes in the three cases (BASE, PRIV and PUB). First, for firms, we expect the highest profits in PUB and the lowest profits in BASE with PRIV in the middle. As we showed in Section 3.2, worker proposals can promote higher wages, profits, and overall efficiency when they provide information about the worker's type. In addition, as we have shown in this section, there will be a higher proportion of workers with low minimum acceptable wages in the population $\left(q^{P U B}>q\right)$ when proposals are made public, which are the type of workers most profitable for the firm. Because of the same reason, we also expect higher worker incomes (i.e., accepted wages) under private proposals. Finally, the condition of Corollary 2 ensures that while every worker would accept the firm offer under private proposals, high type workers would reject it in PUB and in BASE. However, since there are less high type workers in PUB, the acceptance rate will be higher than in BASE.

Corollary 3 (Income inequality across treatments). If $T \in\left(\hat{q}^{P R I V}, q\right]$ then,

(i) Conditional on the wage offer being accepted, income inequality among workers is higher in PRIV than in PUB and BASE.

(ii) Worker's income, as a share of the total surplus, is higher in PRIV than in PUB and BASE.

Corollary 3 follows from the result that the firm offers higher wages to those who ask for it only under private proposals. While workers receive low wage offers regardless of their proposals in PUB or BASE (see Corollary 2). It follows then than under private proposals, the 
percentege of accepted high wages should be higher (Corollary 3.1) and worker's should be able to get a higher share of the total surplus (Corollary 3.2) than in the other two conditions.

\subsection{Testable Predictions}

In this section, we provide testable predictions for our experiments. In our theory, wage proposals convey (imperfect) information about the worker's minimum acceptable wage; therefore, firms would, on average, offer higher wages to those making higher proposals. Our results also indicate that, because workers can misreport, the firm's optimal policy is sometimes to ignore high proposals and offer a low wage instead.

\section{Hypothesis 1: (wage offers and proposals)}

(i) We expect firms' wage-offers to increase in the workers' proposals.

(ii) We expect average wage proposals to be higher than average wage-offers.

(iii) We expect average wage-offers to be higher under proposals.

Our notion of conformity (see Figure 3) implies that the probability that a low-type worker reports their minimum acceptable wage is $\lambda^{P U B}=q(\lambda q)+(1-q)(\lambda q)<\lambda$. Therefore, we expect more misreporting in PUB than in PRIV. On the other hand, our notion of conformity also implies that there will be more low type workers under public proposals and hence workers will be more likely to accept lower wages in PUB than in PRIV and, as we showed in Corollary 2, this will promote firms to offer lower wages in PUB than in PRIV.

\section{Hypothesis 2: (Conformity)}

(i) We expect similar wage proposals in PUB and PRIV.

(ii) We expect higher accepted wages in PRIV than in PUB.

(iii) We expect higher wage offers in PRIV than in PUB.

Under the condition of Corollary 2 we can also make some predictions about how proposals affect firm's profits, worker's income and acceptance rates (and hence overall efficiency).

\section{Hypothesis 3: (Welfare effects)}

(i) We expect workers' income to have the following ranking: PRIV > PUB > BASE.

(ii) We expect firms' profits to have the following ranking: PUB > PRIV > BASE. 
(iii) We expect acceptance rates (and hence overall efficiency) to be higher under both PRIV and PUB proposals than in BASE.

Finally, Corollary 3 also predicts results about income equality.

\section{Hypothesis 4 (Income inequality)}

(i) We expect the share of workers in total surplus to have the following ranking: PRIV $>$ PUB and BASE.

(ii) Conditional on the wage offer being accepted, income equality among workers is higher in PUB and BASE than in PRIV.

\section{Results}

We use both nonparametric statistics and econometric analysis to test our hypotheses. Nonparametric tests (Mann-Whitney one-tailed tests unless otherwise stated) are considered at an individual level to ensure independence. Observations for each individual are averaged for the 15 experimental rounds. To be more conservative with the independence hypothesis nonparametric tests are also conducted at the session level. The econometric analysis (while controlling for additional effects) is conducted using both Random Effects (RE hereafter) Logit and Generalized Least Squared (GLS hereafter) models. We first study wages and proposals with their acceptance rates. This is followed by welfare effects and income equality. Finally, though, we have a limited number of observations for firms, we also explore gender differences.

\subsection{Wages and proposals}

Figure 2 shows firms' (wage) offers and workers' (wage) proposals over time for PRIV and PUB. The relationship of those two variables is positive with correlation coefficient of 0.544 $(p<0.01)$ for PRIV and $0.452(p<0.01)$ for PUB. This confirms Hypothesis 1(i) that the wage offers increase in the wage proposals. Proposals and wage offers, under both PRIV and PUB, have a positive trend over time. Interestingly, as the experiment progresses, the gap between workers' proposals and firms' wage offers is increasing under PUB and is greater than under PRIV. This might be because firms learn over time that, as predicted by our theory, workers are less likely to reject low wage offers in PUB than in PRIV. Note that there is no apparent 
difference between the proposals under PRIV and PUB, however, wage offers under PUB are flatter. This is reflected in the lower correlation coefficient $(0.452)$ between proposals and wage offers under PUB.

Figure 2: Average wage proposals and firms' wage offers over time

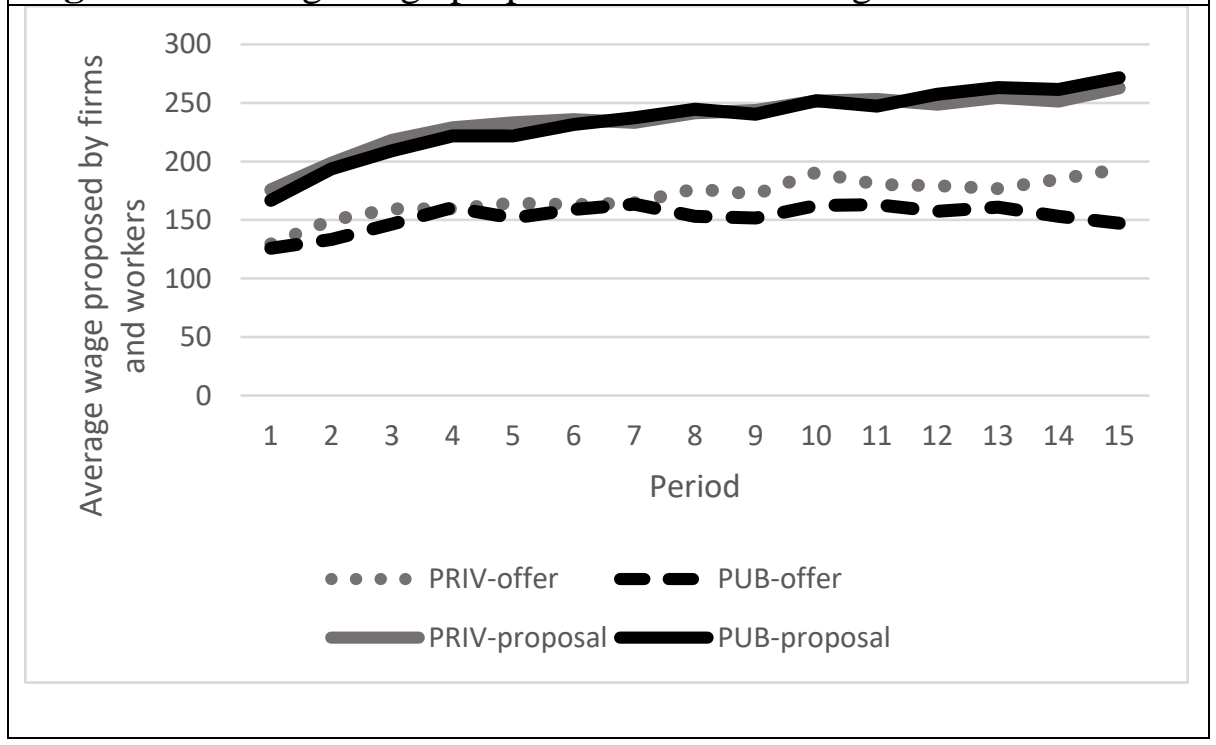

Table 3 contains the descriptive statistics for wage offers and proposals. Differences between proposals and wage offers are positive on average (75.92 for PRIV and 88.44 for PUB). We cannot, however, consider that wage proposals and wage offers are independent. Thus, we conduct a Wilcoxon matched-pairs signed-ranks test and find that proposals are statistically higher than wage offers in each period (PRIV: maximum $p<0.001$; PUB: maximum $\mathrm{p}<0.001$ ). This supports Hypothesis 1 (ii). In Figure 2 above, we can see that this result holds in all 15 periods for both treatments. Consistent with Hypothesis 1 (iii), we see that wage offers by firms are higher (see Table 3) when workers can submit wage proposals (PRIV and PUB) compared to the baseline (PRIV-BASE: $\mathrm{z}=-3.001, \mathrm{p}<0.001$; PUB-BASE: $\mathrm{z}=-0.917, \mathrm{p}=0.017)$.

Next, we focus on the prediction that workers' proposals are affected by a conformity effect in PUB (Hypothesis 2). As predicted by Hypothesis 2 (i), wage proposals are very similar in PUB and PRIV (235.43 vs. $234.66, p=0.956$, two-tailed test). Moreover, in line with Hypothesis 2 (ii), accepted wages in PUB (158.96) are lower than in PRIV (177.17) and this difference is significant $(p=0.003)$. In fact, our notion of conformity also implies that workers should 
misreport more (i.e., propose more than they would accept) in PUB than in PRIV. We find evidence in line with this effect as the difference between proposals and accepted wages is higher in PUB (74.92) than in PRIV (55.38) $(z=-4.159 ; p<0.000)$. Importantly, firms seem to be aware of this effect, because despite observing similar wage proposals, they offer lower wages in PUB (152.77) than in PRIV (170.04); a result supporting Hypothesis 2 (iii) ( $p$ $=0.019)$.

Table 3: Descriptive statistics for average wages and proposals

\begin{tabular}{|l|c|c|c|}
\hline & BASE & PRIV & PUB \\
\hline \% Accepted offers & $75 \%$ & $86 \%$ & $87 \%$ \\
\hline Wage offers by firms & 144.79 & 170.04 & 152.77 \\
\hline Accepted wages by workers & 160.42 & 177.17 & 158.96 \\
\hline Wage proposals by workers & - & 235.43 & 234.66 \\
\hline Proposals - accepted wages & - & 55.38 & 74.92 \\
\hline N(firms/workers) & $25 / 50$ & $24 / 48$ & $24 / 48$ \\
\hline
\end{tabular}

Table 4 presents a series of RE Generalized Least Squares regressions where the dependent variable is the average wage offer made by firms. ${ }^{19}$ The first explanatory variable, given the strong relationship observed in Figure 2 above, is workers' proposal, computed as the average of the two proposals for the workers-firm pair in a given period. To control for heterogeneity, as it is usual in laboratory experiments, we use some of the variables extracted from our post-questionnaire (see experimental section): female, a dummy with value 1 if the firm is female and 0 otherwise; risk lover, a categorical variable that is 0 if the firm is risk averse, 1 if risk neutral and 2 if risk lover; self-reported fair wage, that is, firms' subjective opinion about what they considered to be a fair wage in a post-questionnaire; high income, a dummy with value 1 if the subject is among the $25 \%$ of the subjects living in areas with higher per capita income and 0 otherwise. We also consider the period to control for time trends and the dummies for the BASE and the PRIV treatments.

\footnotetext{
${ }^{19}$ Results qualitatively hold if the dependent variable is the wage offer made by firms to each worker.
} 
We test Hypothesis 1 in specifications 1 and 2. The coefficient associated with worker proposals is positive and significant for both PRIV $(0.412, \mathrm{p}<0.01)$ and $\operatorname{PUB}(0.272, \mathrm{p}<0.01)$. Higher proposals result in higher wage offers and this is independent of whether the proposal is private or public. It is worthwhile to note that the size of the effect under PRIV is much higher than under PUB. This is line with our theoretical model where workers in PUB are affected by conformity and hence, compared to PRIV, they are more likely to make proposals similar to their co-workers. We check this effect by looking at the difference in proposals (for the same firm) for PRIV and PUB. We find that, in line with our conjectures, the average difference in proposals received by each firm in PUB (68.73) is significantly lower than in PRIV (80.07) $(-2.228, \mathrm{p}<0.013)$.

Table 4: RE GLS regressions on wage offers by firms

\begin{tabular}{|c|c|c|c|c|c|}
\hline & PRIV & PUB & BASE vs PRIV & BASE vs PUB & PRIV vs PUB \\
\hline & $(1)$ & (2) & (3) & (4) & $(5)$ \\
\hline Worker proposals & $\begin{array}{c}0.412 * * * \\
(0.055)\end{array}$ & $\begin{array}{c}0.272 * * * \\
(0.044)\end{array}$ & $\begin{array}{c}-9.678 \\
(10.440)\end{array}$ & $\begin{array}{l}-7.688 \\
(9.398)\end{array}$ & $\begin{array}{c}0.323 * * * \\
(0.035)\end{array}$ \\
\hline Female & $\begin{array}{c}-1.844 \\
(12.384)\end{array}$ & $\begin{array}{c}12.076 \\
(10.996)\end{array}$ & $\begin{array}{l}-4.273 \\
(4.361)\end{array}$ & $\begin{array}{l}-3.508 \\
(4.172)\end{array}$ & $\begin{array}{c}3.217 \\
(8.383)\end{array}$ \\
\hline Risk lover & $\begin{array}{l}-3.472 \\
(6.308)\end{array}$ & $\begin{array}{l}-10.004 * \\
(5.298)\end{array}$ & $\begin{array}{c}0.151 \\
(0.105)\end{array}$ & $\begin{array}{l}0.209 * * \\
(0.089)\end{array}$ & $\begin{array}{l}-6.198 \\
(4.110)\end{array}$ \\
\hline $\begin{array}{l}\text { Self-reported fair } \\
\text { wage }\end{array}$ & $\begin{array}{l}-0.044 \\
(0.071)\end{array}$ & $\begin{array}{c}0.198 * * * \\
(0.076)\end{array}$ & $\begin{array}{l}11.270 \\
(9.700)\end{array}$ & $\begin{array}{c}6.187 \\
(10.460)\end{array}$ & \\
\hline High income & $\begin{array}{l}17.059 * \\
(9.314)\end{array}$ & $\begin{array}{l}-2.883 \\
(9.851)\end{array}$ & $\begin{array}{l}1.691 * * * \\
(0.579)\end{array}$ & $\begin{array}{c}0.715 \\
(0.489)\end{array}$ & $\begin{array}{c}6.633 \\
(7.142)\end{array}$ \\
\hline Period & $\begin{array}{l}1.392 * * \\
(0.624)\end{array}$ & $\begin{array}{l}-0.336 \\
(0.711)\end{array}$ & $\begin{array}{l}-21.540 * * \\
(10.29)\end{array}$ & $\begin{array}{l}-8.270 \\
(9.070)\end{array}$ & $\begin{array}{c}0.582 \\
(0.482)\end{array}$ \\
\hline BASE & & & $\begin{array}{c}-21.642 * * \\
(10.289)\end{array}$ & $\begin{array}{l}-8.27 \\
(9.07)\end{array}$ & \\
\hline PRIV & & & & & $\begin{array}{l}12.38 * \\
(6.593)\end{array}$ \\
\hline Constant & $\begin{array}{c}66.686 * * * \\
(19.73) \\
\end{array}$ & $\begin{array}{c}62.467 * * \\
(17.223) \\
\end{array}$ & $\begin{array}{l}129.500 * * * \\
(20.64)\end{array}$ & $\begin{array}{c}112.400 * * * \\
(17.50)\end{array}$ & $\begin{array}{c}76.37 * * * \\
(10.97) \\
\end{array}$ \\
\hline R-squared & 0.188 & 0.314 & 0.225 & 0.221 & 0.176 \\
\hline Observations & 358 & 359 & 732 & 733 & 717 \\
\hline
\end{tabular}

Next, we make pairwise comparisons between treatments. Specification (3) confirms that wage offers were significantly higher in PRIV than in BASE. Although, wages were higher in PUB, they were not significantly different between BASE and PUB (see dummy BASE in specification (4) of Table 4). Our econometric analysis thus finds strong support for Hypothesis 
1(i), (ii) and partly for (iii) (though higher, average wage offers under PUB are not significantly different than BASE). We state Result 1 below based on Hypothesis 1:

\section{$\underline{\text { Result } 1 .}$}

i) Firms' wage-offers increase with workers' wage-proposals.

ii) On average, wage-proposals are higher than wage offers.

iii) Compared to BASE, wage-offers are higher in PRIV and PUB, but only the former difference is statistically significant.

Finally, in specification (5) of Table 4, we confirm that Hypothesis 2 (iii) still holds when we control for other effects (see coefficient 12.38 of the PRIV dummy). We summarize our results for Hypothesis 2 as follows:

\section{Result 2.}

i) Wage proposals are similar in PRIV and PUB.

ii) Accepted wages are higher in PRIV than in PUB.

iii) Wage-offers are higher in PRIV than in PUB.

\subsection{Profits, Efficiency and Income Inequality}

In Table 5, we report descriptive statistics for firm and worker earnings, and income inequality. Relative to the baseline, workers' earnings are higher under both, PRIV and PUB, proposals (PRIV-BASE: $\mathrm{z}=-4.864, \mathrm{p}<0.001$; PUB-BASE: $\mathrm{z}=-2.615, \mathrm{p}=0.004)$. Moreover, workers earn slightly more under PRIV than under PUB (PRIV-PUB: $\mathrm{z}=1.568, \mathrm{p}=0.059$ ). This supports Hypothesis 3 (i). Interestingly, relative to the baseline, firm profits are higher for public and private proposals. The difference, however, is only significant for PUB ( $\mathrm{z}=-2.680$, $\mathrm{p}=0.004)$ and not for PRIV $(\mathrm{z}=-0.160, \mathrm{p}=0.873$, two-tails $)$. Moreover, the highest profits for firms are attained when proposal are public (PRIV-PUB: $z=-3.103 ; p=0.001$ ). Thus, in line with Hypothesis 3 (ii) PUB is the most favourable treatment for firms.

Table 5: Descriptive statistics for profits, efficiency and income inequality 


\begin{tabular}{|l|c|c|c|}
\hline & BASE & PRIV & PUB \\
\hline Firms' earnings & 334.90 & 347.63 & 390.12 \\
\hline Workers' earnings & 116.14 & 144.69 & 134.45 \\
\hline Total earnings & 568.88 & 635.69 & 658.67 \\
\hline Acceptance rates & $75 \%$ & $86 \%$ & $87 \%$ \\
\hline $\begin{array}{l}\text { Workers' surplus } \\
\text { share }\end{array}$ & $20 \%$ & $22 \%$ & $20 \%$ \\
\hline $\begin{array}{l}\text { Gini Index: Overall } \\
\text { Gini Index: workers }\end{array}$ & 0.450 & 0.318 & 0.364 \\
\hline N(firms/workers) & $25 / 50$ & $24 / 48$ & $24 / 48$ \\
\hline
\end{tabular}

Efficiency is only impacted in our framework if a contract between a worker and firm is not realized. This can occur if a worker rejects a wage offer or if a firm makes no wage offer to a worker. In both cases, workers and firms would get zero earnings, resulting in a deadweight loss and lower total surplus (efficiency). We find that acceptance rates are higher (by approximately 10\%) both under PRIV and PUB (PRIV-BASE: $\mathrm{z}=-2.566, \mathrm{p}=0.005$; PUBBASE: $\mathrm{z}=-3.186, \mathrm{p}<0.001)$. This result is consistent with our theoretical framework (Hypothesis 3(iii)) where proposals lead not only to higher wage offers (Hypothesis 1(iii)) but also, in the case of PUB, to a higher chance that the worker would accept a low offer (i.e., of being a "low type"). Finally, overall efficiency does not appear to be different in PUB or PRIV (PRIV-PUB: $\mathrm{z}=1.043, \mathrm{p}=0.297$, two-tailed test $)^{20}$.

We next test Hypothesis 4 by looking at the impact of proposals on income inequality. First, we observe that although efficiency is higher and wages increase when proposals are present, workers' share in total surplus declines when proposals are public (vs private) ( $p=$ 0.024). In fact, and due to the lower proportion of low types in PUB, workers' share in BASE and PUB are not statistically different ( $p=0.223$, two-tails). These results support Hypothesis 4 (i). Next, we consider two additional measures of inequality for all our treatments: overall inequality in the system (i.e., Gini index-overall), which measures how unequal are overall

\footnotetext{
${ }^{20}$ These results are confirmed by the analogous tests at a session level (PRIV-BASE: $p=0.011$, PUB-BASE: $p=0.011$; PUBPRIV: $\mathrm{p}=0.309$, two-tails)
} 
outcomes for both workers and firms, and inequality across workers (Gini index-workers). ${ }^{21}$ Thus, the first measure captures inequality between firms and workers, while the second measure focuses on inequality only across workers. Moreover, to be consistent with our Hypothesis 4 (ii), we will compute the Gini index only for accepted offers ${ }^{22}$.

We obtain the highest (overall) income inequality in BASE (0.450) relative to PRIV (0.318) and PUB (0.364) (see Gini index-overall variable on Table 5). This result is even more striking given that our workers are homogenous, and labor is the only input. We expect these results to be stronger if we include heterogeneity in skill or productivity levels of workers. Our first take from this is that allowing for proposals decreases overall inequality, while, making them public increases it slightly. Regarding income inequality only among workers, we observe a slightly different result. We find that the Gini index-worker is the lower in PRIV (0.157) than PUB (0.164) and BASE (0.172). Thus, making proposals decreases income inequality among workers. These results are only partially consistent with Hypothesis 4 (ii). While our results support the theoretical prediction that making proposals public create a more equal distribution of wages relative to BASE, they are inconsistent with our prediction that PRIV should be the most unequal treatment. Instead, our results show that BASE is the most unequal treatment. One possible explanation for this is that, in contrast to our simplifying assumption of commonly known priors in BASE, firms in our experiments might have had very different preconceived ideas about the workers' minimum acceptable wage. If that is the case, it is likely that wage proposals would decrease inequality in wage offers (and hence in workers earnings) by providing a clearer (if perhaps noisy) signal of the worker's type.

Below, we further conduct some econometric regressions to check the robustness of the previous results on profits, efficiency and income inequality. First, Table 6 contains four RE GLS regressions where the dependent variables are workers' earnings (columns 1- 3) and firms' profits (columns 4-6). The set of independent variables are the same as in Table 5 but now we include a dummy variable to control for treatment effects, PRIV. Notice that in

\footnotetext{
${ }^{21}$ Note that there are several ways to compute the Gini index since we have 15 observations per subject. We compute the Gini index as the average of the 15 periods. We believe this is the best way to capture income inequality since profits and inequality evolves over time and the reference point should be considered within each period.

${ }^{22}$ A remark is in order here. Even though we use proposals, we feel they work as a proxy for the disclosure of wages. In fact, the public disclosure of proposals is weaker than the public disclosure of wages where we can expect a stronger effect. Our main question will be to study how private and public proposals impact wage inequality (if they do).
} 
specifications 1 to 3 all the covariates will refer to workers' characteristics. Thus, worker proposals in specifications 4-6 refers to the average wage proposals made by the workers paired with the corresponding firm. We confirm that workers' profits are higher under proposals. Looking at Table 6, we find that in both cases the coefficients associated with BASE are negative and significant (-25.536 when compared to PRIV and -17.435 when compared to PUB). Nevertheless, there are no significant differences in workers' earnings between private or public proposals. Thus, we find the same results as before.

Table 6: RE GLS regressions on workers' and firms' profits

\begin{tabular}{|c|c|c|c|c|c|c|}
\hline & $\begin{array}{c}\text { BASE and } \\
\text { PRIV }\end{array}$ & $\begin{array}{c}\text { BASE and } \\
\text { PUB }\end{array}$ & $\begin{array}{l}\text { PRIV and } \\
\text { PUB }\end{array}$ & $\begin{array}{c}\text { BASE and } \\
\text { PRIV }\end{array}$ & $\begin{array}{c}\text { BASE and } \\
\text { PUB } \\
\end{array}$ & $\begin{array}{c}\text { PRIV and } \\
\text { PUB }\end{array}$ \\
\hline & (1) workers & (2) workers & (3) workers & (4) firms & (5) firms & (6) firms \\
\hline \multirow[t]{2}{*}{ Female } & 0.309 & $13.277 * *$ & -4.793 & -24.826 & -18.938 & -10.48 \\
\hline & $(5.545)$ & $(6.039)$ & $(6.247)$ & (17.839) & (16.646) & $(14.52)$ \\
\hline \multirow[t]{2}{*}{ Risk lover } & - & - & - & 9.307 & 4.453 & -0.208 \\
\hline & & & & $(7.354)$ & $(8.073)$ & $(6.286)$ \\
\hline Self-reported & $0.126 * * *$ & $0.106^{* *}$ & $0.142 * *$ & -0.193 & -0.204 & $-0.120 *$ \\
\hline Fair-wage & $(0.044)$ & $(0.045)$ & $(0.057)$ & $(0.163)$ & $(0.142)$ & $(0.070)$ \\
\hline \multirow[t]{2}{*}{ High income } & $-13.478 * *$ & 6.426 & -5.266 & 7.653 & 15.630 & 5.597 \\
\hline & $(6.543)$ & (6.183) & $(7.211)$ & (14.583) & (15.738) & (12.69) \\
\hline $\begin{array}{l}\text { Worker's } \\
\text { proposal }\end{array}$ & - & - & $\begin{array}{c}0.146 * * * \\
(0.037)\end{array}$ & - & - & $\begin{array}{c}-0.743 * * * \\
(0.097)\end{array}$ \\
\hline \multirow[t]{2}{*}{ Period } & $2.605 * * *$ & $1.371 * * *$ & $2.132 * * *$ & 1.641 & $2.156^{*}$ & $3.033^{* * *} *$ \\
\hline & $(0.451)$ & $(0.399)$ & $(0.456)$ & $(1.267)$ & $(1.245)$ & (1.018) \\
\hline \multirow[t]{2}{*}{ BASE } & $-25.536 * * *$ & $-17.435 * * *$ & - & -20.432 & $-50.638 * * *$ & - \\
\hline & $(5.178)$ & $(5.687)$ & & (16.427) & $(15.711)$ & \\
\hline \multirow[t]{2}{*}{ PRIV } & - & - & 4.852 & - & - & $-36.61 * * *$ \\
\hline & & & $(6.542)$ & & & (14.01) \\
\hline \multirow[t]{2}{*}{ Constant } & $95.608 * * *$ & $90.947 * * *$ & $57.40 * * *$ & $380.453 * * *$ & $08.203 * * *$ & $564.9 * * *$ \\
\hline & (10.717) & & $(11.15)$ & & $(29.833)$ & $(24.11)$ \\
\hline R-squared & 0.317 & 0.211 & 0.272 & 0.149 & 0.285 & 0.284 \\
\hline Observations & 1470 & 1470 & 1470 & 735 & 735 & 735 \\
\hline
\end{tabular}

Looking at firm earnings ((3) to (6)) (where all covariates refer to firms' characteristics), we find that, although they are higher under proposals, this effect is only significant when proposals are public. That is, firms' profits are significantly higher in PUB than in PRIV (see coefficient of PRIV in (6)). This is also what we found with the nonparametric statistical tests. Hypothesis 3 (ii) is thus supported except that PUB and PRIV are not significantly different, while Hypothesis 3(ii) is also partially supported with the exception of the relationship of BASE and PRIV. 
Next, we focus on efficiency. Table 7 presents a series of RE GLS regressions where the dependent variable is efficiency ( 1 if two contracts are accepted, 0.5 if only one worker accepted the offer and, 0 when no contract is accepted). We consider an additional dummy for the PRIV treatment. We compare PRIV and BASE in specification (1) and PUB and BASE in specification (2). Clearly, efficiency in BASE is significantly lower than in PUB or PRIV (see coefficient of BASE dummy in specifications (1) and (2)). However, efficiency is not significantly different in PUB and PRIV (see coefficient of PRIV dummy in specification (3)) when controlling for other explanatory variables and exploiting all the information of the panel data structure. Thus, Hypothesis 3 (iii) is again supported.

Table 7: RE GLS regressions on efficiency

\begin{tabular}{|c|c|c|c|}
\hline & BASE and PRIV & BASE and PUB & PRIV and PUB \\
\hline & $(1)$ & $(2)$ & $(3)$ \\
\hline \multirow[t]{2}{*}{ Female } & -0.066 & -0.049 & -0.005 \\
\hline & $(0.049)$ & $(0.040)$ & $(0.038)$ \\
\hline \multirow[t]{2}{*}{ Risk lover } & 0.003 & -0.003 & -0.024 \\
\hline & $(0.020)$ & $(0.020)$ & $(0.018)$ \\
\hline \multirow[t]{2}{*}{ Self-reported fair wage } & 0.00004 & 0.0002 & 0.035 \\
\hline & $(0.0004)$ & $(0.0003)$ & $(0.030)$ \\
\hline \multirow[t]{2}{*}{ High income } & 0.044 & 0.040 & 0.0001 \\
\hline & $(0.040)$ & $(0.040)$ & $(0.0002)$ \\
\hline \multirow[t]{2}{*}{ Period } & $0.009 * * *$ & $0.006 * *$ & $0.006 * * *$ \\
\hline & $(0.002)$ & $(0.003)$ & $(0.002)$ \\
\hline \multirow[t]{2}{*}{ BASE } & $-0.096 * *$ & $-0.111 * * *$ & \\
\hline & $(0.044)$ & $(0.04)$ & \\
\hline \multirow[t]{2}{*}{ PRIV } & & & -0.039 \\
\hline & & & $(0.035)$ \\
\hline \multirow[t]{2}{*}{ Constant } & $0.763 * * *$ & $0.766 * * *$ & $0.788 * * *$ \\
\hline & $(0.092)$ & $(0.072)$ & $(0.051)$ \\
\hline R-squared & 0.137 & 0.192 & 0.105 \\
\hline Observations & 735 & 735 & 720 \\
\hline
\end{tabular}

Next, we turn our attention to income inequality. In Table 9, we analyse it among workers using a RE GLS model where we consider two dependent variables. For specifications (1) to (3), the dependent variable is the distance between each workers income in a period minus the average incomes of all the workers in that period and treatment in absolute value but, restricted to those cases where there was an offer and it was accepted. For specifications (4) to (6), the dependent variable is the distance between each workers income in a period minus the average profits of all the workers and firms in that treatment in absolute value. 
Table 9: RE GLS on the distance between workers' earnings and average earnings of all workers; and the distance between average earnings of all workers and firms in a treatment.

\begin{tabular}{|c|c|c|c|c|c|c|}
\hline & \multicolumn{3}{|c|}{ Only workers } & \multicolumn{3}{|c|}{ Workers and firms } \\
\hline & $\begin{array}{c}(1) \\
\text { BASE and } \\
\text { PRIV }\end{array}$ & $\begin{array}{c}(2) \\
\text { BASE and } \\
\text { PUB }\end{array}$ & $\begin{array}{c}(3) \\
\text { PRIV and } \\
\text { PUB }\end{array}$ & $\begin{array}{c}(4) \\
\text { BASE and } \\
\text { PRIV }\end{array}$ & $\begin{array}{c}(5) \\
\text { BASE and } \\
\text { PUB }\end{array}$ & $\begin{array}{c}(6) \\
\text { PRIV and } \\
\text { PUB }\end{array}$ \\
\hline Female & $\begin{array}{c}-8.172 * * \\
(3.837)\end{array}$ & $\begin{array}{c}-7.117 * * \\
(3.494)\end{array}$ & $\begin{array}{c}-7.366 * * \\
(3.266)\end{array}$ & $\begin{array}{l}-0.309 \\
(5.546)\end{array}$ & $\begin{array}{c}-13.280^{* *} \\
(6.039)\end{array}$ & $\begin{array}{c}6.699 \\
(6.485)\end{array}$ \\
\hline High income & $\begin{array}{l}-1.036 \\
(3.810)\end{array}$ & $\begin{array}{c}0.874 \\
(3.414)\end{array}$ & $\begin{array}{c}1.793 \\
(3.719)\end{array}$ & $\begin{array}{c}13.480 * * \\
(6.543)\end{array}$ & $\begin{array}{l}-6.426 \\
(6.183)\end{array}$ & $\begin{array}{c}5.322 \\
(7.503)\end{array}$ \\
\hline $\begin{array}{l}\text { Self-reported } \\
\text { fair wage }\end{array}$ & $\begin{array}{c}0.063^{* *} \\
(0.031)\end{array}$ & $\begin{array}{c}0.070^{* *} \\
(0.029)\end{array}$ & $\begin{array}{c}0.152 * * * \\
(0.026)\end{array}$ & $\begin{array}{c}-0.126 * * * \\
(0.044)\end{array}$ & $\begin{array}{l}0.106^{* *} \\
(0.045)\end{array}$ & $\begin{array}{c}-0.219 * * * \\
(0.424)\end{array}$ \\
\hline Period & $\begin{array}{c}-1.254 * * * \\
(0.288)\end{array}$ & $\begin{array}{c}-1.172 * * * \\
(0.269)\end{array}$ & $\begin{array}{c}-0.545^{* *} \\
(0.266)\end{array}$ & $\begin{array}{c}-2.605 * * * \\
(0.451)\end{array}$ & $\begin{array}{c}-1.371 * * * \\
(0.399)\end{array}$ & $\begin{array}{c}-2.906 * * * \\
(0.272)\end{array}$ \\
\hline BASE & $\begin{array}{c}8.226 * * \\
(3.573)\end{array}$ & $\begin{array}{c}11.68 * * * \\
(3.222)\end{array}$ & & $\begin{array}{c}-43.470 * * * \\
(5.178)\end{array}$ & $\begin{array}{c}-74.110 * * * \\
(5.687)\end{array}$ & \\
\hline PRIV & & & $\begin{array}{c}1.517 \\
(3.377)\end{array}$ & & & $\begin{array}{c}-25.100 * * * \\
(6.817)\end{array}$ \\
\hline Constant & $\begin{array}{c}45.200 * * * \\
(7.884) \\
\end{array}$ & $\begin{array}{c}38.39 * * * \\
(7.065) \\
\end{array}$ & $\begin{array}{c}15.670 * * * \\
(5.900)\end{array}$ & $\begin{array}{c}540.50 * * * \\
(10.72) \\
\end{array}$ & $\begin{array}{c}567.70^{* * * *} \\
(10.13)\end{array}$ & $\begin{array}{c}588.60 * * * \\
(11.71) \\
\end{array}$ \\
\hline R-squared & 0.125 & 0.278 & 0.283 & 0.086 & 0.200 & 0.199 \\
\hline Observations & 1,135 & 1,156 & 1,197 & 1470 & 1470 & 1440 \\
\hline
\end{tabular}

First, if we focus on income inequality only amongst workers, we find that inequality is significantly higher in BASE relative to PRIV and PUB treatments (see coefficient of the dummy BASE in (1) and (2)). However, income inequality is not significantly different for public or private proposals (see coefficient of the dummy PRIV in (3)). Thus, the econometric analysis supports Hypothesis 4 (ii) partially (except for PUB and PRIV that are not significantly different). ${ }^{23}$ When we analyze inequality in overall terms ((4) to (6)), we observe that income inequality is significantly lower in BASE than in PUB or PRIV. This result clearly contradicts what we found in Table 5 according to the Gini index (overall). The most plausible explanation is that even though workers earn higher wages with proposals, this effect is dominated by the increase in firms' earnings due to higher acceptance rates in the presence of proposals. Finally, when proposals are private income inequality is lower that when they are public. This is in line

\footnotetext{
${ }^{23}$ Table $\mathrm{C} 1$ in Appendix $\mathrm{C}$ reports similar results when we measure income inequality as the proportion from the total surplus earned by firms.
} 
what we found in Table 5 above. We summarize our findings in Result 3 (Hypothesis 3) and Result 4 (Hypothesis 4) below:

\section{$\underline{\text { Result } 3 .}$}

i) Workers earn more under proposals (PUB and PRIV) relative to BASE.

ii) Relative to BASE, proposals increase firms' profits under proposals. There are no significant differences in proposals between PRIV and PUB

iii) Acceptance rates (and therefore efficiency) are higher under proposals. Although, efficiency is the highest under public proposals, this is not significant when controlling for other effects.

\section{Result 4:}

i) Workers' share of total surplus is higher in PRIV than in PUB or BASE. Income inequality measured through the Gini index is the highest in BASE.

ii) Income inequality among workers, conditional on the wage-offer to be accepted, is higher in BASE than in PUB or PRIV.

\subsection{Gender Analysis}

Our experiment also provides some interesting results regarding gender effects that we discuss in this section. We begin by summarizing the key papers in this literature and discuss how they relate to our experiment. We then use these findings to provide an empirical hypothesis regarding gender effects in our experiment. We finish by testing this hypothesis with our experiment results.

The experimental literature on gender differences in negotiation presents mixed results. Eckel and Grossman (2001) used the ultimatum game to study the gender gap in an environment where participants know their partner's gender (opposite to our setting). They found that compared to men, women's wage offers are higher, while, as second movers, they are also more likely to accept wages. Solnick (2001) performs an ultimatum game experiment with two treatments, one where the partner's gender is known and another when it is unknown. Similar to Eckel and Grossman's results, he found that when gender is salient, males receive higher offers. By contrast, there are no gender differences in wage offers when the gender of the partner is unknown. However, in contrast to Eckel and Grossman's findings, females were more likely to reject offers. A possible explanation for these different results is that Solnick's 
experiment followed the strategy method and hence the impact of rejection decisions on the overall outcome is less obvious.

García-Gallego, Georgantzís and Jaramillo-Gutiérrez (2012) also study gender differences in an ultimatum game. However, in their setup participants don't know their partner's gender. They have three treatments and in two of them workers have to perform a real effort task. We focus on the treatment where there is no real effort task. Though not significant, and contrary to Eckel and Grossman (2001), they find that women offer less and reject more they find that. As we did not inform subjects about their partner's gender or use the strategy method, our work is more closely related to García-Gallego, Georgantzís and Jaramillo-Gutiérrez (2012). Finally, in what it is perhaps the most related experimental paper, Rigdon (2012) uses a Demand Ultimatum Game where partner's gender was unknown. She finds that, when proposals are made privately, females make significantly lower wage proposals than males and accept wage offers more frequently. However, the gender gap disappears when proposals were made public. Note that, Rigdon's environment is related to our PRIV and PUB treatments. ${ }^{24}$ Based on the findings of this literature, we state the following empirical hypothesis:

\section{Empirical hypothesis G: Gender}

(i) Compared to males, female workers will make lower wage proposals in PRIV but similar in PUB (Rigdon, 2012).

(ii) Compared to males, female firms will make similar wage offers in BASE (GarcíaGallego, Georgantzís and Jaramillo-Gutiérrez, 2012) but lower in PRIV and similar in PUB (Rigdon 2012).

(iii) Compared to males, female workers' acceptance rates will be similar in BASE (GarcíaGallego, Georgantzís and Jaramillo-Gutiérrez, 2012) but higher in PRIV and similar in PUB (Rigdon, 2012).

Table 11 reports the descriptive statistics by gender for each treatment. Although, not statistically significant ( $p=0.415$, two-tails) we observe that in line with Hypothesis $\mathrm{G}$ (ii),

\footnotetext{
${ }^{24}$ There is also an extensive literature on gender and negotiation which is not so close to our setting either because the partner's gender is known or because the game is not an Ultimatum Game: Dittrich, Knabe and Leipold (2014) use a face-to-face alternating-offers wage bargaining environment and they find that male workers receive on average higher wage offers. Also, male workers ask higher salaries than females when they make a counteroffer to firms. Hernandez-Arenaz and Iriberri (2018), in a real word TV negotiation game, find that when the strong bargaining position is held by men, and they bargain against women responders, men are more likely to take a larger share of the pie. Meanwhile, women demand less from men than from women.
} 
wage offers are $12 \%$ lower for females than males in BASE. Additionally, in line with this hypothesis, we do not find gender differences in wage offers when proposals are present (PRIV: 172.27 vs 169.15; PUB: 152.62 vs. 152.89 ) (PRIV: $p=0.634$ and PUB: $p=0.655$, two-tails). ${ }^{25}$

Table 11: Descriptive statistics by gender

\begin{tabular}{|l|c|c|c|c|c|c|}
\hline & \multicolumn{2}{|c|}{ BASE } & \multicolumn{2}{c|}{ PRIV } & \multicolumn{2}{c|}{ PUB } \\
\hline & Male & Female & Male & Female & Male & Female \\
\hline \% Accepted offers & $64 \%$ & $84 \%$ & $86 \%$ & $85 \%$ & $81 \%$ & $91 \%$ \\
\hline Wage offers & 152.39 & 136.33 & 172.27 & 169.15 & 152.62 & 152.89 \\
\hline Accepted wages & 167.17 & 155.60 & 183.63 & 169.96 & 161.10 & 157.58 \\
\hline Proposals & - & - & 243.45 & 226.71 & 227.41 & 239.85 \\
\hline Firms' profits & 353.17 & 315.11 & 357.56 & 343.53 & 388.54 & 392.76 \\
\hline Workers' income & 105.41 & 127.68 & 151.8 & 136.95 & 128.34 & 138.82 \\
\hline $\begin{array}{l}\text { N } \\
\text { (firms/workers) }\end{array}$ & $13 / 24$ & $12 / 26$ & $7 / 25$ & $17 / 23$ & $15 / 20$ & $9 / 28$ \\
\hline
\end{tabular}

We do not find any differences for average wage proposals (PRIV: $p=0.353$; PUB: $p$ $=0.347$ ), a result that it is only partially in line with Hypothesis G (i). ${ }^{26}$ Although not statistically significant, it seems that, compared to men, women make lower proposals in PRIV, but higher in PUB, a result consistent with Rigdon's (2012) finding that women are more assertive in wage negotiations when they have access to public information. Indeed, if we explore the evolution over time of these variables (Figure 3), we observe that average wage proposals by women are below those of men in every period when proposals are private (Figure 3a)), while the opposite happens when proposals are public (Figure 3b)).

Figure 3: Evolution in time of wage proposals by male and female workers
a) Private proposals
b) Public proposals

\footnotetext{
${ }^{25}$ In fact, this result also holds if we consider data just from the first 5 periods (BASE: $p=0.211$; PRIV: $p=$ 0.949 , two-tails) except for PUB where the difference is weakly significant and male started with offers slightly higher than women (PUB: $p=0.080$ ).

${ }^{26}$ Again, this result also holds if we consider data just from the first 5 periods (PRIV: $p=0.279$, two-tails; PUB: $p=0.490$, two-tails).
} 


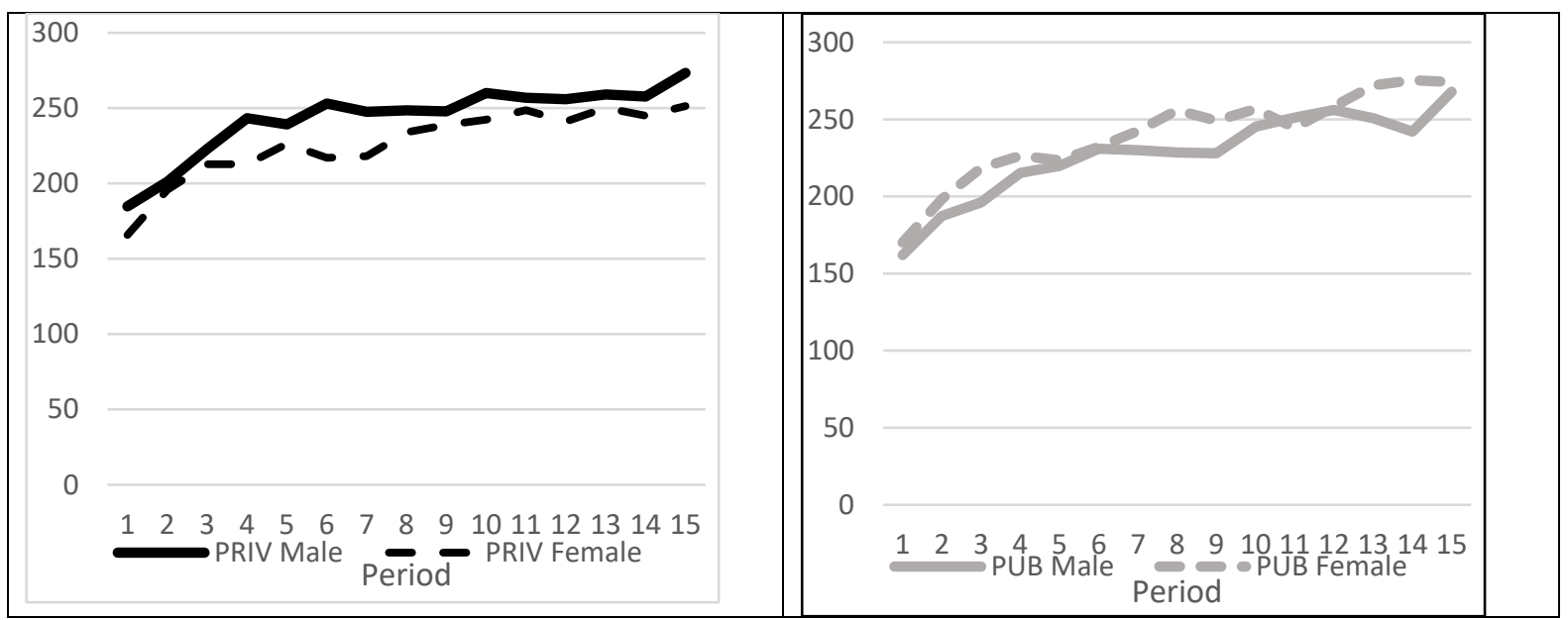

Regarding acceptance rates, female workers accept significantly more offers than males in BASE $(p<0.001)$, a result that supports Hypothesis $\mathrm{G}$ (iii). ${ }^{27}$ Compared to males, females also have higher acceptance rates in PUB $(p=0.018)$, but similar in PRIV $(p=0.902$, twotails). This is consistent with the second part of Hypothesis G (iii). Therefore, our results support Hypothesis G (iii). Finally, we do not find significant gender differences in firm profits or worker income except in BASE where female workers receive higher income than males, a result that follows the female's higher acceptance rates. ${ }^{28} \mathrm{We}$ summarize our findings on gender below:

\section{$\underline{\text { Result } 5}$}

In the absence of proposals (BASE), we find gender differences in rejection rates, workers' profits and efficiency. With the exception of rejection rates, these differences disappear when private (PRIV) and public (PUB) proposals are present.

\section{Conclusion}

In this paper, we have experimentally and theoretically studied the impact of pre-play communication and information in a labour relationship. Pre-play communication is observed in many job negotiations but their impact in wage formation is little understood. Further, providing information on salaries has recently been explored in many countries and the European Union $^{29}$ in an attempt to make the labour markets more transparent. In our main

\footnotetext{
${ }^{27}$ Note that García-Gallego, Georgantzís and Jaramillo-Gutiérrez (2012) find that women reject more although not significantly. We get the opposite, women reject (quantitatively) less but not significantly. A possible explanation is that García-Gallego, Georgantzís and Jaramillo-Gutiérrez (2012) consider a fixed matching while we consider a random one.

${ }^{28}$ For firms' profits: $p=0.889$ in BASE, $p=0.427$ in PRIV, $p=0.612$ in PUB, all tests two-tails. For workers' profits: $p=$ 0.038 in BASE, $p=0.252$ in PRIV, $p=0.369$ in PUB, all tests two-tails.

29 https://www.eleconomista.es/legislacion/noticias/11242527/05/21/La-ley-obligara-a-informar-del-sueldo-antes-de-laentrevista.html?fbclid=IwAR1ps57ZgHdETU8Wc146ngBAKPkfoZeEL5AkdvexzPTbJAblp1HbEyHMv4c
} 
treatments, workers made wage proposals that were either private or public in a subsequent treatment. Wage proposals were non-binding and hence cheap talk. We, however, find that simply making proposals has important implications for workers and firms.

Our results indicate that pre-play communication matters and promotes higher average wage offers relative to the baseline without proposals. We have also shown that making proposals public increases firm profits. As predicted by the theoretical model, both private and public proposals lower rejection rates and hence increase efficiency relative to the baseline. This is an important result, as it shows that non-binding pre-play communication has nontrivial welfare implications. We also explore the effects on income distribution. While workers earn more under proposals, wage proposals decrease income inequality. In fact, workers income is the most unequal in the baseline (without proposals). Finally, we also provide some evidence that making a proposal, whether public or private, eliminates gender bias in acceptance rates.

Our experiment also reveals another element of making wage proposals public. Even though average wages increase under proposals, they increase by a greater amount when proposals are private. Thus, we find that making worker wages public mainly benefits the firm. This is because publicly available proposals generate a conformity effect where workers are less likely to reject, which decreases wages relative to the case where proposals are made privately.

The previous result is contrary to popular belief as indicated by the motivation behind some policy measures that have been recently gaining increased attraction. These relate to wage disclosure policies in organizations to address income inequality with emphasis on fair remuneration $^{30}$ or wage disclosure for the sake of transparency (a la California, Switzerland, Norway or Denmark) ${ }^{31}$. For example, the UK (since January 1, 2019) has a pay disclosure policy where its biggest companies have to disclose and explain every year their top bosses pay and the gap between that and their average worker. Similar measures have also been

\footnotetext{
${ }^{30} \mathrm{https} / / / \mathrm{www} . c i p d . c o . u k / k n o w l e d g e /$ strategy/reward/pay-fairness-reporting-factsheet

31 See for example, https://www.gov.uk/government/news/new-executive-pay-transparency-measures-come-into-force, https://www.forbes.com/sites/jackkelly/2019/11/21/the-growing-movement-to-make-employees-salaries-public-for-all-tosee/?sh=68cb40a97bb8,https://time.com/5353848/salary-pay-transparency-work/and https://www.nytimes.com/interactive/2020/02/19/magazine/salary-sharing.html.
} 
adopted in several countries such as Norway, Sweden, Finland and states in US ${ }^{32}$. Further, recently the EU commission has presented a proposal as regards wage transparency that aims to guarantee the same wages for the same work and to address gender discrimination. We find that while the use of public proposals eliminates many gender differences, making information public for proposals works to the benefit of the firms.

Our paper is a first step in trying to understand the complicated interaction between public and private information in labour markets and its subsequent impact on worker wages, firm profits and overall efficiency. While inequality in salaries in the workplace is a growing policy concern, it is, however, not clear its wider implications towards work performance and well-being will be. It remains as an open question what the effect of wage proposals in the labor market will be when effort levels are considered.

\section{References:}

Agell, J., \& Bennmarker, H. (2003). Endogenous wage rigidity. Available at SSRN 466582.

Akerlof, G. A. (1982). Labor contracts as partial gift exchange. The Quarterly Journal of Economics, 97(4), 543-569.

Anderson, L. R., \& Holt, C. A. (1997). Information cascades in the laboratory. American Economic Review, 847-862.

\footnotetext{
${ }^{32}$ Eleven US states have a legislation which makes non-disclosure clauses illegal.
} 
Asch, S. E. (1961). Effects of group pressure upon the modification and distortion of judgments. In Documents of gestalt psychology (pp. 222-236). University of California Press.

Banerjee, A. V. (1992). A simple model of herd behavior. The Quarterly Journal of Economics, 107(3), 797-817.

Bernheim, B. D. (1994). A theory of conformity. Journal of Political Economy, 102(5), 841877.

Bewley, T. F., \& Bewley, T. F. (2009). Why wages don't fall during a recession. Harvard University Press.

Blount, S., \& Bazerman, M. H. (1996). The inconsistent evaluation of absolute versus comparative payoffs in labor supply and bargaining. Journal of Economic Behavior \& Organization, 30(2), 227-240.

Bottino, E., García-Muñoz, T., Goddio, C., \& Kujal, P. (2016). What is a fair wage? Reference points, entitlements and gift exchange. Journal of Behavioral and Experimental Economics, 63, 125-135.

Du Caju, P., Gautier, E., Momferatou, D., \& Ward-Warmedinger, M. E. (2008). Institutional features of wage bargaining in 23 European countries, the US and Japan. Banque de France Working Paper No. 228

Cai, H., Chen, Y., \& Fang, H. (2009). Observational learning: Evidence from a randomized natural field experiment. American Economic Review, 99(3), 864-82.

Camerer, Colin F. (2015) "The promise and success of lab-field generalizability in experimental economics: A reply to Levitt and List." Ch 14. In G. Frechette and A. Schotter (Eds.) Handbook of Experimental Economic Methodology. Oxford: Oxford Univ. Press. DOI:10.1093/acprof:oso/9780195328325.001.0001

Camerer, C. F. (2011). Behavioral game theory: Experiments in strategic interaction. Princeton University Press.

Cameron, L. A. (1999). Raising the stakes in the ultimatum game: Experimental evidence from Indonesia. Economic Inquiry, 37(1), 47-59.

Carpenter, J. P., \& Seki, E. (2005). Competitive work environments and social preferences: Field experimental evidence from a Japanese fishing community. The BE Journal of Economic Analysis \& Policy, 5(2).

Charness, G., Cobo-Reyes, R., Jiménez, N., Lacomba, J. A., \& Lagos, F. (2012). The hidden advantage of delegation: Pareto improvements in a gift exchange game. American Economic Review, 102(5), 2358-79.

Charness, G., Cobo-Reyes, R., Lacomba, J. A., Lagos, F., \& Pérez, J. M. (2016). Social comparisons in wage delegation: Experimental evidence. Experimental Economics, 19(2), 433-459. 
Cialdini, R. B., \& Goldstein, N. J. (2004). Social influence: Compliance and conformity. Annu. Rev. Psychol., 55, 591-621.

Clark, A. E., \& Oswald, A. J. (1998). Comparison-concave utility and following behaviour in social and economic settings. Journal of Public Economics, 70(1), 133-155.

Cox, J. C., \& Isaac, R. M. (1986). Incentive regulation: A case study in the use of laboratory experimental analysis in economics.

Crosetto, P., \& Filippin, A. (2013). The "bomb" risk elicitation task. Journal of Risk and Uncertainty, 47(1), 31-65.

Cullen, Z. B., \& Pakzad-Hurson, B. (2021). Equilibrium effects of pay transparency. National Bureau of Economic Research (No. w28903).

Dittrich, M., Knabe, A., \& Leipold, K. (2014). Gender differences in experimental wage negotiations. Economic Inquiry, 52(2), 862-873.

Dyer, D., Kagel, J. H., \& Levin, D. (1989). A comparison of naive and experienced bidders in common value offer auctions: A laboratory analysis. The Economic Journal, 99(394), 108-115.

Eckel, C. C., \& Grossman, P. J. (2001). Chivalry and solidarity in ultimatum games. Economic Inquiry, 39(2), 171-188.

Exley, C. L., Niederle, M., \& Vesterlund, L. (2020). Knowing when to ask: The cost of leaning in. Journal of Political Economy, 128(3), 816-854.

Falk, A., Fehr, E., \& Zehnder, C. (2006). Fairness perceptions and reservation wages-the behavioral effects of minimum wage laws. The Quarterly Journal of Economics, 121(4), 13471381.

Farrell, J., \& Rabin, M. (1996). Cheap talk. Journal of Economic Perspectives, 10(3), 103118.

Fatas, E., Heap, S. P. H., \& Arjona, D. R. (2018). Preference conformism: An experiment. European Economic Review, 105, 71-82.

Fehr, E., Kirchsteiger, G., \& Riedl, A. (1993). Does fairness prevent market clearing? An experimental investigation. The Quarterly Journal of Economics, 108(2), 437-459.

Fehr, E., Fischbacher, U., \& Tougareva, E. (2002). Do high stakes and competition undermine fairness? Evidence from Russia. Evidence from Russia (July 2002).

Franke, J., Gurtoviy, R., \& Mertins, V. (2016). Workers' participation in wage setting: A giftexchange experiment. Journal of Economic Psychology, 56, 151-162.

Festinger, L., Schachter, S., \& Back, K. (1950). Social pressures in informal groups. New York: Harper and Brothers. 
Fischbacher, U. (2007). z-Tree: Zurich toolbox for ready-made economic experiments. Experimental Economics, 10(2), 171-178.

García-Gallego, Aurora, N. Georgantzís and Jaramillo-Gutiérrez, A. (2012). Gender differences in ultimatum games: Despite rather than due to risk attitudes, Journal of Economic Behavior \& Organization, 83, 42- 49

Gneezy, U. (2005). Deception: The role of consequences. American Economic Review, 95(1), 384-394.

Greiner, B. (2015). Subject pool recruitment procedures: organizing experiments with ORSEE. Journal of the Economic Science Association, 1(1), 114-125.

Goeree, J. K., \& Yariv, L. (2015). Conformity in the lab. Journal of the Economic Science Association, 1(1), 15-28.

Güth, W., Schmidt, C., \& Sutter, M. (2007). Bargaining outside the lab-a newspaper experiment of a three-person ultimatum game. The Economic Journal, 117(518), 449-469.

Hernandez-Arenaz, I., \& Iriberri, N. (2018). Women ask for less (only from men): Evidence from bargaining in the field. Journal of Economic Behavior \& Organization, 152, 192-214.

Jeworrek, S., \& Mertins, V. (2014). Do Self-Determined Wages Really Improve Employees Performance? Evidence from a Randomized Field Experiment.

Kahneman, D., Knetsch, J. L., \& Thaler, R. (1986). Fairness as a constraint on profit seeking: Entitlements in the market. American Economic Review, 76(4), 728-741.

Karlan, D. S. (2005). Using experimental economics to measure social capital and predict financial decisions. American Economic Review, 95(5), 1688-1699.

Kessler, J., \& Vesterlund, L. (2015). The external validity of laboratory experiments: The misleading emphasis on quantitative effects (Vol. 18, pp. 392-405). Oxford, UK: Oxford University Press.

Lundquist, T., Ellingsen, T., Gribbe, E., \& Johannesson, M. (2009). The aversion to lying. Journal of Economic Behavior \& Organization, 70(1-2), 81-92.

Muchnik, L., Aral, S., \& Taylor, S. J. (2013). Social influence bias: A randomized experiment. Science, 341(6146), 647-651.

Rassenti, S. J., \& Smith, V. L. (1986). Electric Utility Deregulation. Pricing Electric, Gas and Telecommunication Services. The Institute for the Study of Regulation.

Rassenti, S. J., Smith, V. L., \& Wilson, B. J. (2002). Demand-side bidding will reduce the level and volatility of electricity prices. The Independent Review, 6(3), 441-445.

Rigdon, M. L. (2012). An experimental investigation of gender differences in wage negotiations. Available at SSRN 2165253. 
Sliwka, D. (2007). Trust as a signal of a social norm and the hidden costs of incentive schemes. American Economic Review, 97(3), 999-1012.

Slonim, R., \& Roth, A. E. (1998). Learning in high stakes ultimatum games: An experiment in the Slovak Republic. Econometrica, 66(3), 569-596.

Solnick, S. J. (2001). Gender differences in the ultimatum game. Economic Inquiry, 39(2), 189-200.

Toplak, M. E., West, R. F., \& Stanovich, K. E. (2014). Assessing miserly information processing: An expansion of the Cognitive Reflection Test. Thinking \& Reasoning, 20(2), 147-168.

Thöni, C., \& Gächter, S. (2015). Peer effects and social preferences in voluntary cooperation: A theoretical and experimental analysis. Journal of Economic Psychology, 48, 72-88.

Yamamori, T., Kato, K., Kawagoe, T., \& Matsui, A. (2008). Voice matters in a dictator game. Experimental Economics, 11(4), 336-343. 


\title{
APPENDIX \\ Appendix A1: Instructions for PRIV treatment ${ }^{33}$
}

\section{General instructions}

You are taking part in an economic experiment. Please read the following instructions carefully. Depending upon the decisions you make you can earn additional money in addition to the 3 Euros fee for your participation. It is extremely important that you read the instructions carefully.

\begin{abstract}
Absolutely no communication whatsoever is allowed in the course of the experiment. Please address questions you might have to us directly. Any violation of this will lead to the exclusion from both the experiment and all payments.
\end{abstract}

This experiment consists of companies and employees. Each individual will be assigned randomly the role of a company, or employee, and will maintain the same role during the entire experiment.

The entire experiment comprises of 15 periods. In each period, each company will be randomly matched with two employees.

The identity of the employees will not be disclosed to any company before or after the experiment. Likewise, employees will not know with which firm they have been paired or the identity of other employees who are assigned to the same company as them.

\section{Decisions in each period}

At the beginning of each period, the company will receive a salary proposal from her two potential employees. The salary proposal is not binding, that is, companies can decide whether to make the proposed offer, another offer or no offer. The proposals will be private, that is, each employee will only know his proposal (not the one of the other employee).

After learning the salary proposals, the company can submit a salary offer separately to one, or both, employees, or submit no offer at all. Each offer received by an employee is known only to them.

Once an employee learns the salary offer and its amount, they will have to decide whether to accept or reject it. Employees will never know whether the company they are paired with has submitted an offer to the other employee.

Employees learn only the amount of their own salary offer. They don't know if the company submitted any other salary offers. If, for instance, a company submits a salary offer to one employee and a different one to the other employee, none of the employees will learn the other employee's offer.

\footnotetext{
${ }^{33}$ Instructions for other treatments are available upon request.
} 
The company's income in each period

When an offer is accepted, the employee and the company close a contract. This will generate the following income for the company:

- If the company concludes a contract with the two employees, she will achieve an income of 780 points - salary offered to employee 1 - salary offered to employee 2.

- If the company concludes a contract with one employee, she will achieve an income of $\mathbf{3 9 0}$ points - the salary offered to the employee who accepted the offer.

- If the company concludes no contract at all (because she has not made an offer or because her offers has not been accepted), she will achieve an income of zero points.

The employee's income in each period

- If no offer of salary is submitted to you, your income amounts to zero.

- If you accept the salary offer, your income will be the amount of the salary offered.

- If you reject the salary offer, your income will be zero.

EXAMPLES of how income is calculated in a period

1. The employee 1 makes a salary proposal of 70 points and employee 2 of 150 points. The company submits two salary offers, 120 points to employee 1 and 120 points to employee 2. Both reject the offer:

-Income for the company: 0

-Income for the employees: 0

2. The employee 1 makes a salary proposal of 250 points and employee 2 of 100 points. The company submits two salary offers to the two employees, 80 points to employee 1 and 200 to employee 2. If both accept the offer:

-Income for the company: $780-80-200=500$

-Income for employee 1: 80

-Income for employee 2: 200

3. The employee 1 makes a salary proposal of 65 points and employee 2 of 220 points. The company submits a salary offer to employee 1 of 180 points. If employee 1 accepts the offer:

-Income for the company: $390-180=210$

-Income for employee 1: 180 
-Income for employee 2: 0

\section{Please note:}

- The salary you offer to be paid to the employee only if the offer is actually accepted.

- The above mentioned rules apply to all companies and all employees. They are known to each company and to each employee.

\section{How to make your decision}

All decisions will be made on the screen. At the beginning of each period, you will be shown the following screen for companies:

On this screen, the company will have to decide whether to submit a salary offer to each employee. To do so, the company must click either "Yes" or "No" in the respective input fields.

If the company clicks "Yes" for a particular employee, then she will be asked to enter the amount of the salary offer she wants to make to that particular employee.

If the company clicks "No", that particular employee will not get a salary offer.

The permitted numbers for salary offers are between 0 and 390:

$$
0 \leq \text { salary offer } \leq 390
$$

Once the company has made her decision(s) and entered the input, she must click the OK button. Important, the company can revise her decisions as long as the OK button is not activated. 
To finish this stage, the company must click on the "NEXT" button (on the right bottom corner).

The following screen shows the decision that the employee will have to make in the event that they have received a salary offer:

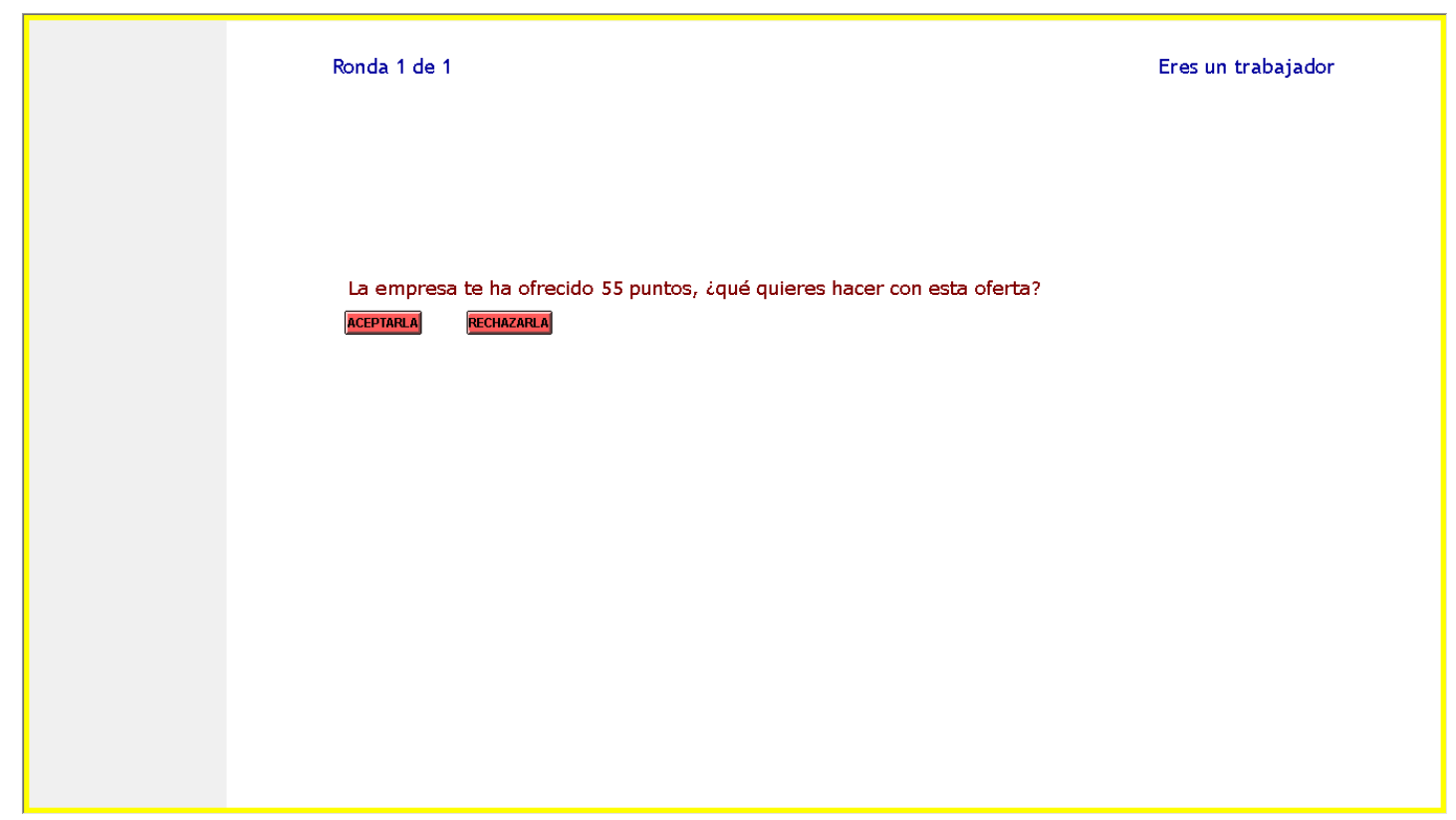

On this screen, the employee will be informed of the exact amount of the offer. Afterwards, the employee must decide whether to accept or reject the offer by clicking on "accept" or "reject".

If the employee has not received an offer, the message "The company has decided not to make any offer to you in this period" will appear.

The income for that period will then appear on the screen.

This concludes the period. In the following period, each company will be randomly assigned two new employees. At the end of each period, the company will be able to see the salary offers of each employee and the income of the previous periods. Employees will see the offers received (only their own) and their income from previous periods.

Before starting the experiment, we will tell you on the computer screen the equivalence between points and Euros.

You will only be paid the points corresponding to a randomly chosen round by rolling a die. 


\section{Appendix A2: Control Questions for PRIV and PUB treatments ${ }^{34}$}

It is mandatory to answer every question. Wrong answers have no consequences. Address any questions to us!

1. Employee 1 makes a wage proposal of 100 points and employee 2 of 120 . The company does not make wage offers to any of the employees. What is the income in points for,

- The company: 0

- Each of the employees: 0

2. Employee 1 makes a wage proposal of 80 points and employee 2 of 120 . The company sends wage offers to employee 1 and 2 for a value of 250 points. What is the income in points for,

(a) Both employees accept the offer. What is the income in points for,

- The company: 280

- Each of the employees: 250

(b) Employee 1 accepts the offer and 2 rejects it. What is the income in points for,

- The company:140

- Employee 2: 0

3. Employee 1 makes a wage proposal of 30 points and employee 2 of 70 . The company sends a wage offer for a value of 30 pints to employee 1 and a wage offer of 60 points to employee 2. What is the income in points if,

(a) Both employees accept the offer. What is the income in points for,

- The company: 690

- Each of the employees: 60

(b) Employee 1 accepts the offer and 2 rejects it. What is the income in points for,

\footnotetext{
${ }^{34}$ Control questions for Baseline are available upon request.
} 
- The company:360

- Employee 1: 30

(c) Both employees reject the offer. What is the income in points for,

- The company: 0

- Each of the employees: 0

\section{Appendix A3: Post-questionnaire}

In this questionnaire we ask you to give us some general information about yourself. After carefully reading each section, we ask you to answer by writing an " $\mathrm{x}$ " in the appropriate box. Please, answer all the questions.

Thank you for participating!

\section{General information:}

1. Date of birth:
2. Gender: a) Male:
b) Female:

3. School and Degree that you study at the university:

School

Degree

4. What is the zip code of your parents' house?

5. If Juan can drink a barrel of water in 6 days and Maria can drink a barrel in 12 days, how long do they need to drink a barrel between the two of them?

6. Juan receives the fifteenth highest grade in his class and at the same time the fifteenth lowest grade in his class. How many students are there in class?

7. A man buys a pig for $€ 60$, sells it for $€ 70$, buys it again for $€ 80$, and finally sells it for $€$ 90. How much money has he made?

8. Simon decides to invest $€ 8,000$ in shares one day at the beginning of 2018 . Six months after investing, on July 17 , the shares he bought decrease in value by $50 \%$. Fortunately, from July 
17 to October 17, the shares you have purchased increase in value by $75 \%$. At this moment, Simon
a. did not win or lose anything in the stocks market,
b. his shares have a higher value tan when he started,
c. he lost money (his shares lost value)

9. Imagine that you are participating in a program in which you have to decide how many boxes to open out of a total of 100 numbered boxes. All boxes contain $€ 10$ except one that has $€ 0$. You do not know where the box with no money is, only that it can be in any of the 100 boxes with the same probability. The boxes are opened in numerical order. If, for example, you decide to open 20 boxes, the boxes ranging from 1 to 20 will be opened; If, for example, you decide to open 57, all the boxes between 1 and 57 will be collected.

How many boxes would you decide to open in this situation?

10.- What do you think is the appropriate salary for a worker? (Remind that it must be a number between 0 and 390):

11.- If you have participated in the experiment as a company and you have chosen different salaries for your two workers in the same period, why have you done it? (If you have not been a company, please write "I am a worker").

12.- If you have participated in the experiment as a worker, what is the minimum wage you would be willing to accept? (If you have not been a worker, please write "I am a company").

13.- Do you think it is difficult for you to recognize your mistakes?

Yes

No 


\section{Appendix B: Theory Proofs}

Proof of Proposition 1: The firm's optimal decision is to offer the low wage if $\left(M-w_{m}^{L}\right) q \geq$ $M-w_{m}^{H}$; otherwise, she will offer the high wage. Thus, $w_{o}^{B A S E}=\left\{\begin{array}{ll}w_{m, L} & \text { if } q \geq T \\ w_{m, H} & \text { if } q<T\end{array}\right.$. The rest of the Proposition follows immediately from this.

Proof of Proposition 2: Applying Bayes rule we can compute the firm's belief that the worker is low type given the prior $(q)$ and the observation that his proposal was high:

$$
\hat{q}^{P R I}:=P\left(w_{m, L} \mid w_{p}=w_{m, H}\right)=\frac{P\left(w_{p}=w_{m, H} \mid w_{m, L}\right)}{P\left(w_{p}=w_{m, H}\right)} q
$$

where $P\left(w_{p}=w_{m, H} \mid w_{m, L}\right)=(1-\lambda)$ and $P\left(w_{p}=w_{m, H}\right)=1-q \lambda$

Therefore, when observing a high proposal, the firm's optimal decision is to offer a low wage if $\left(M-w_{m}^{L}\right) \hat{q}^{P R I} \geq M-w_{m}^{H}$; otherwise, she will offer a high wage. Thus, if we denote by $\widetilde{w}_{o}^{P R I}$ to be the optimal wage when observing a high proposal, we get $\widetilde{w}_{o}^{P R I}=$ $\begin{cases}w_{m, L} & \text { if } \hat{q}^{P R I} \geq T \\ w_{m, H} & \text { if } \hat{q}^{P R I}<T\end{cases}$

And because the firm always matches the proposal of the low type (which is fully revealing), the optimal firm's policy is:

$$
w_{o}^{P R I}= \begin{cases}w_{m, L} & \text { if } w_{p}=w_{m, L} \\ \widetilde{w}_{o}^{P R I} & \text { if } w_{p}=w_{m, H}\end{cases}
$$

The rest of the proposition follows immediately from this.

Proof of Corollary 1: First note that $\hat{q}^{P R I}<q$ and hence, when comparing PRI and BASE there are three possible cases: 
(i) $\quad T \leq \hat{q}^{P R I}$

In this case, $\widetilde{w}_{o}^{P R I}=w_{o}^{B A S E}=w_{m, L}$ which means that, regardless of proposals, wage offers are the same in both cases, $w_{O}^{P R I}=w_{o}^{P R I}=w_{m, L}$, and this leads to the same firms profits $\Pi_{F}^{P R I}=\Pi_{F}^{B A S E}$; workers income $\Pi_{W}^{P R I}=\Pi_{W}^{B A S E}$ and acceptance rates $r^{P R I}=r^{B A S E}=q$.

(ii) $T>q$

In this case, $\widetilde{w}_{o}^{P R I}=w_{o}^{B A S E}=w_{m, H}$. Therefore, expected firm's profits are:

$$
\begin{gathered}
\Pi_{F}^{P R I}=q \lambda\left(M-w_{m, L}\right)+(1-q \lambda)\left(M-w_{m, H}\right)=M-w_{m, H}+q \lambda\left(w_{m, H}-w_{m, L}\right) \\
>\Pi_{F}^{B A S E}=M-w_{m, H}
\end{gathered}
$$

Expected worker's incomes are:

$$
\Pi_{W}^{P R I}=q \lambda w_{m, L}+(1-q \lambda) w_{m, H}=w_{m, H}-q \lambda\left(w_{m, H}-w_{m, L}\right)>\Pi_{W}^{B A S E}=w_{m, H}
$$

And acceptance rates are: $r^{P R I}=r^{B A S E}=1$

$$
\text { (iii) } \quad T \in\left(\hat{q}^{P R I}, q\right]
$$

In this case, $\widetilde{w}_{O}^{P R I}=w_{m, H}>w_{o}^{B A S E}=w_{m, L}$. Therefore, firm's profits in PRI are (see case ii): $\Pi_{F}^{P R I}=M-w_{m, H}+q \lambda\left(w_{m, H}-w_{m, L}\right)$ while expected firm's profits in BASE are: $\Pi_{F}^{B A S E}=$ $q\left(M-w_{m, L}\right)$ where $\Pi_{F}^{P R I}>\Pi_{F}^{B A S E}$ iff $M(1-q)>w_{m, H}(1-q \lambda)-q w_{m, L}(1-\lambda)$. Note that for this condition not to hold $w_{m, H}$ should be relatively close to $M$ (i.e., $M$ sufficiently low) in which case $T>q$ and hence condition (iii) would not hold.

Expected worker's incomes are: $\Pi_{W}^{P R I}=w_{m, H}-q \lambda\left(w_{m, H}-w_{m, L}\right)>\Pi_{W}^{B A S E}=q w_{m, L}$

And acceptance rate are: $r^{P R I}=1>q=r^{B A S E}$

Proof of Proposition 3: Applying Bayes rule we can compute the firm's belief that the worker is low type given the prior $\left(q^{P U B}\right)$, and the observation that his proposal was high:

$$
\hat{q}^{P U B}:=P\left(w_{m}^{P U B}=w_{m, L} \mid w_{p}=w_{m, H}\right)=\frac{P\left(w_{p}=w_{m, H} \mid w_{m}^{P U B}=w_{m, L}\right)}{P\left(w_{p}=w_{m, H}\right)} q^{P U B}
$$


where $P\left(w_{p}=w_{m, H} \mid w_{m}^{P U B}=w_{m, L}\right)=(1-\lambda q)$ and $P\left(w_{p}=w_{m, H}\right)=1-\lambda q q^{P U B}$.

Therefore, when observing a high proposal, the firm's optimal decision is to offer a low wage if $\left(M-w_{m}^{L}\right) \hat{q}^{P U B} \geq M-w_{m}^{H}$; otherwise, she will offer a high wage. Thus, if we denote by $\widetilde{w}_{O}^{P U B}$ to be the optimal wage when observing a high proposal, we get $\widetilde{w}_{o}^{P U B}=$ $\begin{cases}w_{m, L} & \text { if } \hat{q}^{P U B} \geq T \\ w_{m, H} & \text { if } \hat{q}^{P U B}<T\end{cases}$

And because the firm always matches the proposal of the low type (which is fully revealing), the optimal firm's policy is:

$$
w_{o}^{P U B}= \begin{cases}w_{m, L} & \text { if } w_{p}=w_{m, L} \\ \widetilde{w}_{o}^{P U B} & \text { if } w_{p}=w_{m, H}\end{cases}
$$

The rest of the proposition follows immediately from this.

Proof of Corollary 2: First note that $\hat{q}^{P U B}>\hat{q}^{P R I}$ because $q^{P U B}>q$. Moreover, $\hat{q}^{P U B}>q$ and $\hat{q}^{P R I}<q$. Therefore, $\hat{q}^{P U B}>q>\hat{q}^{P R I}$. From Propositions 1-3, we know that if $\hat{q}^{P U B}>$ $q>T>\hat{q}^{P R I}$, then $w_{o}^{B A S E}=w_{m, L}\left(\right.$ Proposition 1); $\widetilde{w}_{o}^{P R I}=w_{m, H}($ Proposition 2) and $\widetilde{w}_{o}^{P U B}=w_{m, L}$ (Proposition 3). The rest of the Corollary follows immediately from these optimal wage offers.

Proof of Corollary 3: It follows immediately from Corollary 2 and the arguments in the text. 